\title{
Safe cholecystectomy multi-society practice guideline and state-of-the-art consensus conference on prevention of bile duct injury during cholecystectomy
}

\author{
L. Michael Brunt ${ }^{1} @$ - Daniel J. Deziel ${ }^{2} \cdot$ Dana A. Telem $^{3} \cdot$ Steven M. Strasberg ${ }^{1} \cdot$ Rajesh Aggarwal $^{4}$. \\ Horacio Asbun ${ }^{5}$. Jaap Bonjer ${ }^{6}$. Marian McDonald ${ }^{7}$. Adnan Alseidi ${ }^{8} \cdot$ Mike Ujiki $^{9} \cdot$ Taylor S. Riall $^{10}$. Chet Hammill ${ }^{1}$. \\ Carol-Anne Moulton ${ }^{11}$. Philip H. Pucher ${ }^{12} \cdot$ Rowan W. Parks $^{13}$. Mohammed T. Ansari ${ }^{14}$ - Saxon Connor ${ }^{15}$.

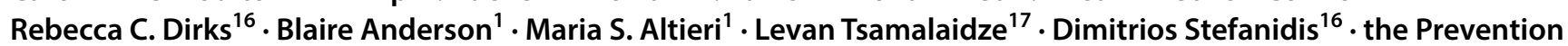 \\ of Bile Duct Injury Consensus Work Group
}

Received: 19 December 2019 / Accepted: 10 April 2020

(c) Society of American Gastrointestinal and Endoscopic Surgeons (SAGES) and Wolters Kluwer 2020

\begin{abstract}
Background Bile duct injury (BDI) is the most common serious complication of laparoscopic cholecystectomy. To address this problem, a multi-society consensus conference was held to develop evidenced-based recommendations for safe cholecystectomy and prevention of BDI.

Methods Literature reviews were conducted for 18 key questions across six broad topics around cholecystectomy directed by a steering group and subject experts from five surgical societies (SAGES, AHPBA IHPBA, SSAT, and EAES). Evidencebased recommendations were formulated using the GRADE methodology. When evidence-based recommendations could not be made, expert opinion was documented. A number of recommendations for future research were also documented. Recommendations were presented at a consensus meeting in October 2018 and were voted on by an international panel of 25 experts with greater than $80 \%$ agreement considered consensus.

Results Consensus was reached on 17 of 18 questions by the Guideline Development Group (GDG) and expert panel with high concordance from audience participation. Most recommendations were conditional due to low certainty of evidence. Strong recommendations were made for (1) use of intraoperative biliary imaging for uncertainty of anatomy or suspicion of biliary injury; and (2) referral of patients with confirmed or suspected BDI to an experienced surgeon/multispecialty hepatobiliary team.

Conclusion These consensus recommendations should provide guidance to surgeons, training programs, hospitals, and professional societies for strategies that have the potential to reduce BDIs and positively impact patient outcomes. Development of clinical and educational research initiatives based on these recommendations may drive further improvement in the quality of surgical care for patients undergoing cholecystectomy.
\end{abstract}

Keywords Cholecystectomy $\cdot$ Laparoscopic cholecystectomy $\cdot$ Bile duct injury $\cdot$ Gallstones $\cdot$ Patient safety

\section{Background}

Cholecystectomy is the most common operation performed worldwide by general surgeons with between 750,000 and $1,000,000$ performed in the U.S. annually. Laparoscopic

Electronic supplementary material The online version of this article (https://doi.org/10.1007/s00464-020-07568-7) contains supplementary material, which is available to authorized users.

\section{Michael Brunt}

Bruntm@wustl.edu

Extended author information available on the last page of the article cholecystectomy (LC) was introduced into clinical practice approximately 30 years ago, and it quickly became the gold standard operation for patients with symptomatic gallstones [1]. Because the benefits of laparoscopic compared to open cholecystectomy were so dramatic and readily apparent to both surgeons and patients, a "laparoscopic revolution" 
ensued that changed the face of surgery. However, there was a downside to the adoption of this procedure by an entire generation of surgeons who had no training in laparoscopic surgery, namely an increase in the number of bile duct injuries (BDI) [2-4].

When one considers the high rate of wound, cardiac, pulmonary, and other complications, as well as pain and delayed return to work and activity that accompanied open cholecystectomy when it was the standard treatment for gallstone disease, laparoscopic cholecystectomy has been an incredible advance. Today, the vast majority of patients who undergo LC have an uneventful and rapid recovery and complete return to full activity within days of their procedure. Although with advances in instrumentation, imaging, and surgical technique the incidence of BDI with $\mathrm{LC}$ has decreased somewhat in recent years, this complication still occurs at a frequency higher than the $0.1-0.2 \%$ rate reported in the open cholecystectomy era $[5,6]$.

Several recent large studies that have examined BDI and laparoscopic cholecystectomy have found major BDI rates of $0.15-0.36 \%$ and an overall biliary complication rate of $1.5 \%$ if bile leaks are included [7-12]. In one study of the Gallriks database in Sweden, which captures $>90 \%$ of all cholecystectomies in that country, the rate of major BDI that required reconstruction was $0.36 \%$ and overall biliary complications were observed in $1.5 \%$ of patients [13]. In the U.S.A., administrative database studies have found an incidence of major BDI of $0.15-0.3 \%$ [7, 9, 10, 12], but
Fig. 1 PRISMA search flow diagram demonstrating selection, screening, inclusion, and exclusion of articles for review. See Online Appendix 4 for studies not included in evidence synthesis

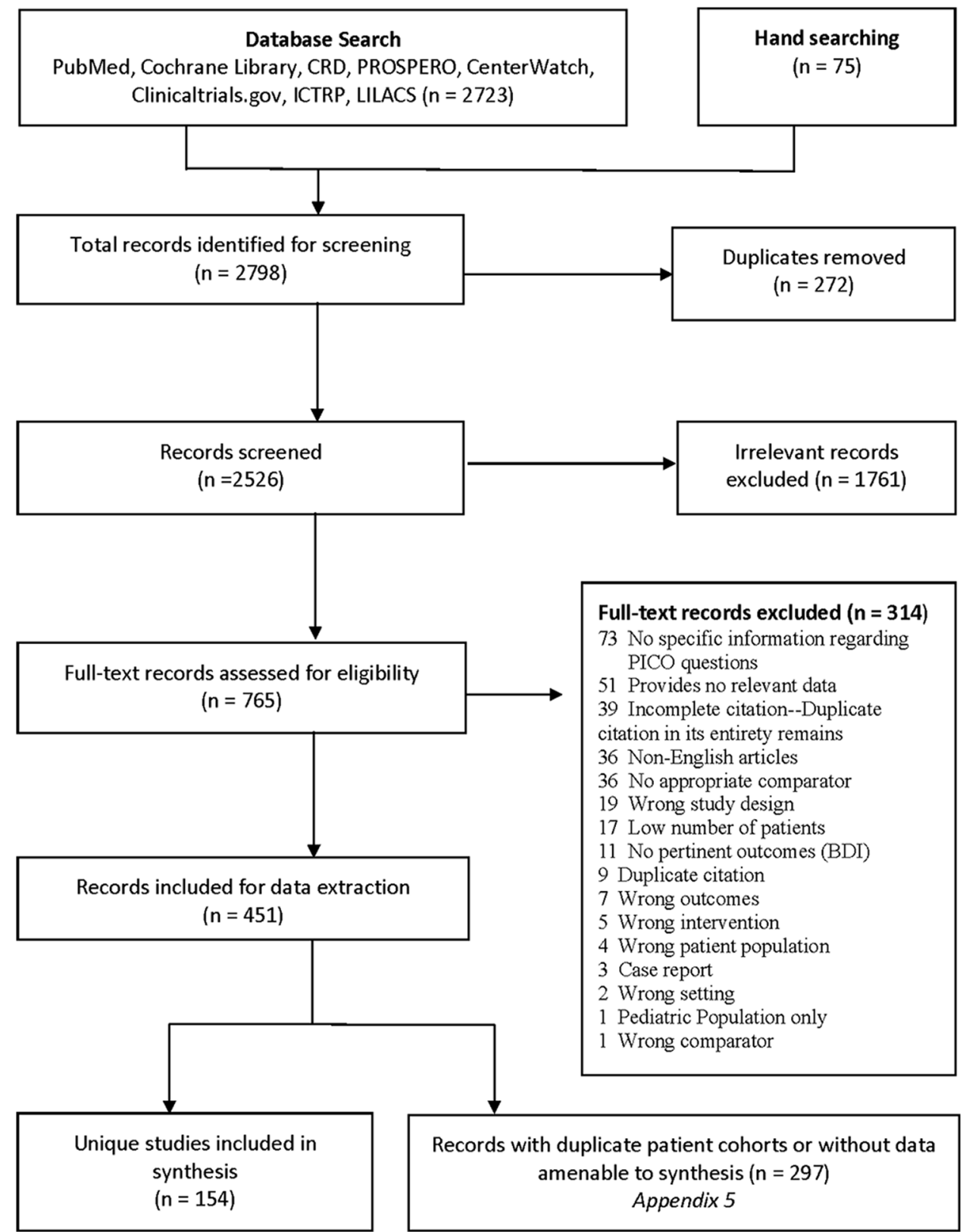




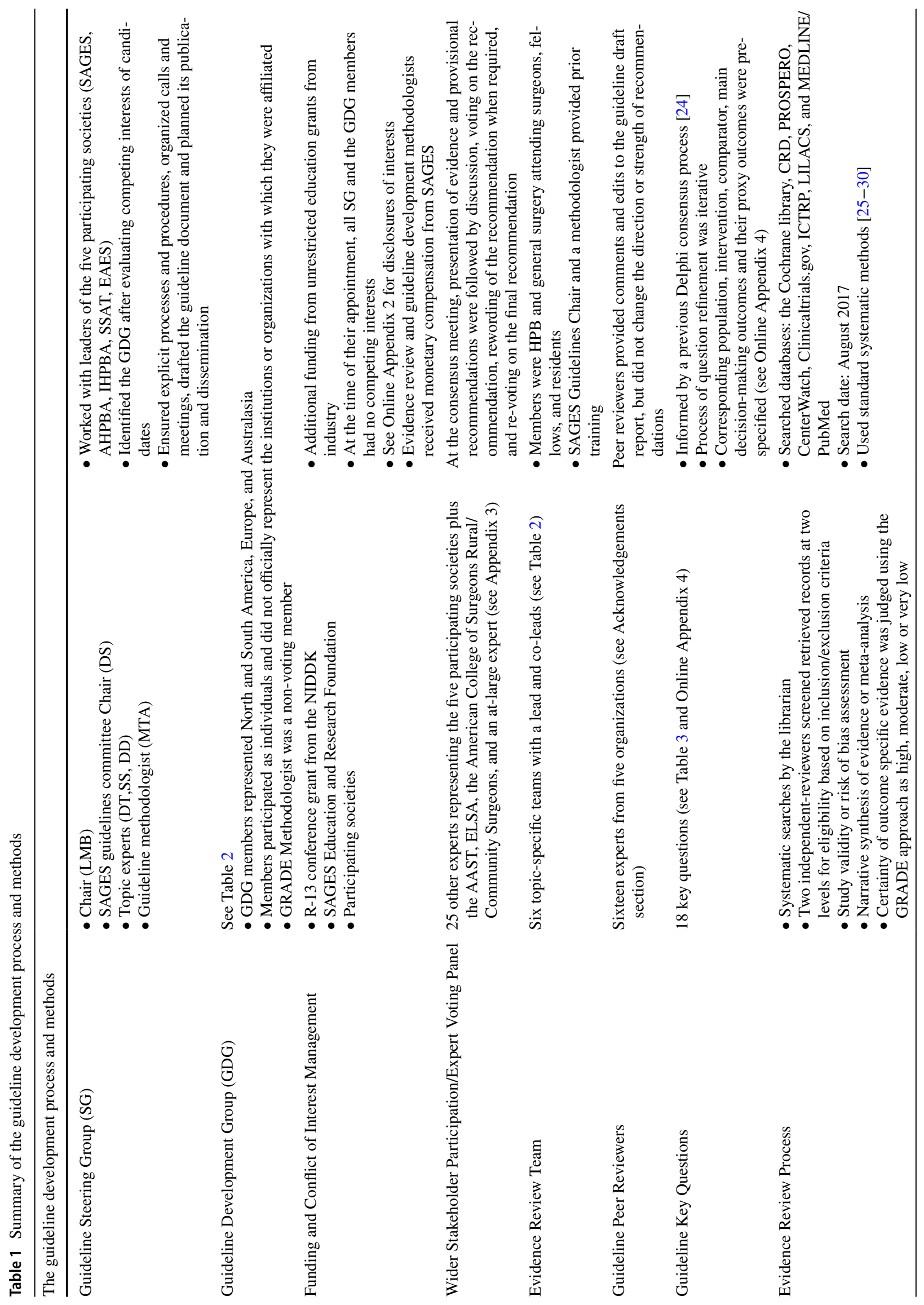




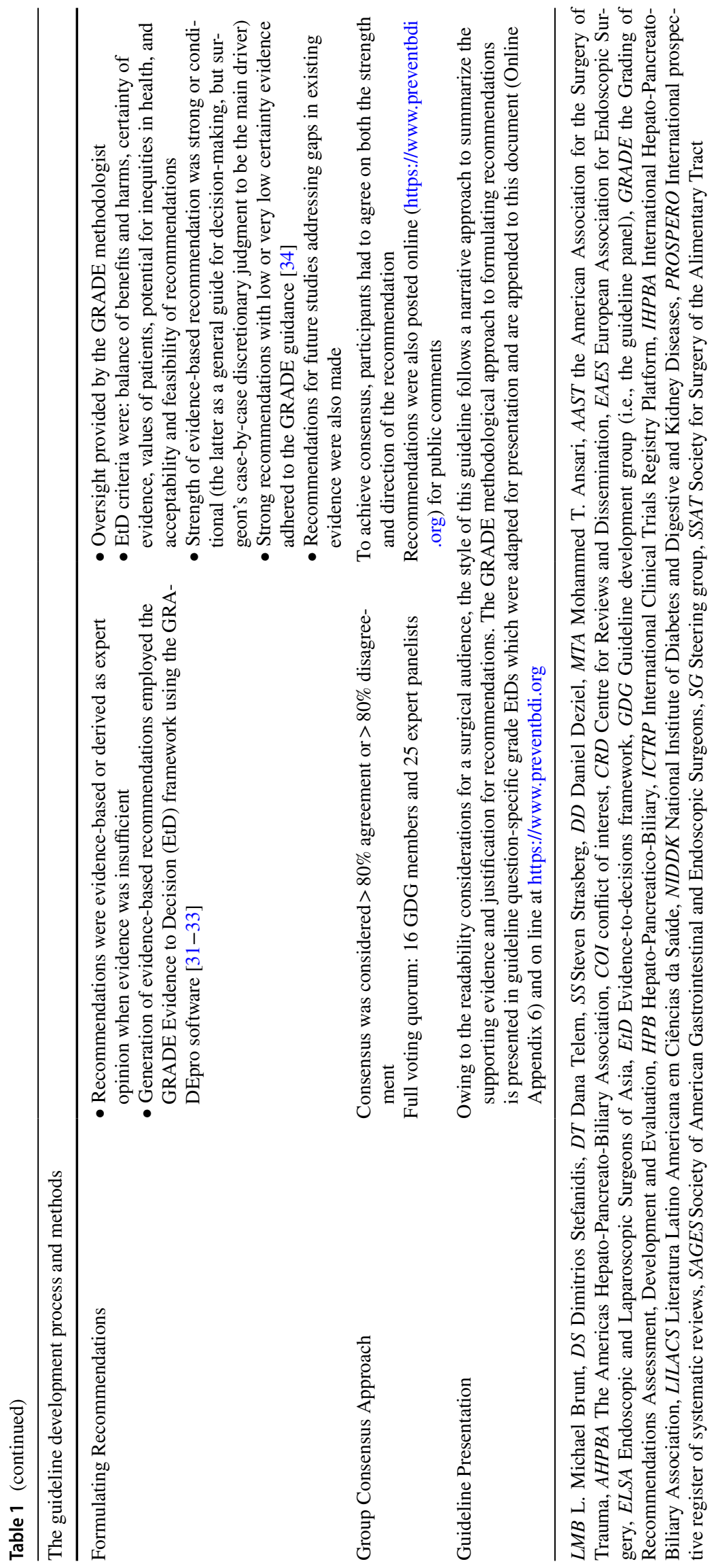


Table 2 Guideline development group (leads and co-leads) and working group members

\begin{tabular}{|c|c|c|c|c|}
\hline Group & Guideline question \# & Lead & Co-leads & Working group members \\
\hline 1 & $1,2,3$ & Dan Deziel & Marian McDonald & $\begin{array}{l}\text { Maria Altieri, Ben Veenstra, Justin Gerard, Ismael Domiguez- } \\
\text { Rosado, MacKenzie Landin }\end{array}$ \\
\hline 2 & 4,5 & Michael Brunt & Adnan Alseidi Mike Ujiki & $\begin{array}{l}\text { Tim Schaffner, Eugene Ceppa, Sadiq Sikora, Sara Holden, Shanley } \\
\text { Deal, Alessandro Paganini, Bailey Su }\end{array}$ \\
\hline 3 & $6,7,9$ & Dana Telem & Taylor Riall & $\begin{array}{l}\text { Daniel Hashimoto, Chris Davis, Marie Crandall, Charles Lawrence, } \\
\text { Chantal den Bakker, Leonie van Gastel }\end{array}$ \\
\hline 4 & 8,11 & Steven Strasberg & $\begin{array}{l}\text { Chet Hammill } \\
\text { Saxon Connor }\end{array}$ & $\begin{array}{l}\text { Blaire Anderson, Chet Hammill, Megan Thomas, Scott Dojels, } \\
\text { Waala Abdelmoaty }\end{array}$ \\
\hline 5 & $10,12-17$ & Raj Aggarwal & Carol Anne Moulton & $\begin{array}{l}\text { Phil Pucher, Fernando Santos, Nate Stoikes, Romeo Ignacio, Ryan } \\
\text { Campagna, Sara Monafred, Domenech Asbun }\end{array}$ \\
\hline 6 & 18 & Horacio Asbun & $\begin{array}{l}\text { Rowan Parks } \\
\text { Jaap Bonjer }\end{array}$ & $\begin{array}{l}\text { Ewen Harrison, Luigi Boni, Oscar Imventarza, Rohan Jeyarajah, } \\
\text { Marc Mesleh, Levan Tsalamaidze, Eline Zwart }\end{array}$ \\
\hline
\end{tabular}

Table 3 Guideline questions for prevention of bile duct injury during cholecystectomy (CCX)

1. Should the critical view of safety (CVS) vs. another (infundibular, top down, IOC) be used to mitigate the risk of BDI during laparoscopic cholecystectomy (LC)?

2. Should the "fundus-first" (top down) technique of total cholecystectomy vs. subtotal cholecystectomy be used when the CVS cannot be achieved?

3. Should the CVS be documented during laparoscopic cholecystectomy with still doublet photos vs. operative notes vs. video?

4. Should intraoperative biliary imaging (intraoperative cholangiography, US) vs. no intraoperative biliary imaging be used to mitigate the risk or severity of bile duct injury during laparoscopic cholecystectomy?

5. Should intraoperative near-infrared biliary imaging vs. IOC or white light be used in limiting the risk of BDI?

6. Should surgical risk stratification vs alternative or no risk stratification be used for mitigating the risk of BDI?

7. Should risk stratification that accounts for cholecystolithiasis vs. no/alternate risk stratification be used for mitigating the risk of BDI?

8. Should immediate cholecystectomy (within $72 \mathrm{~h}$ from symptom onset) vs. CCX delayed beyond $72 \mathrm{~h}$ ( $72 \mathrm{~h}$ to 10 days vs. 6-12 weeks vs. $>12$ weeks) be used for acute cholecystitis?

9. Should subtotal CCX vs. total laparoscopic or open CCX be used for mitigating the risk of BDI in marked acute inflammation or chronic biliary inflammatory fusion (BIF)?

10. Should 4-port lap cholecystectomy vs. reduced port/single incision LC vs robotic LC be used for limiting the risk or severity of BDI?

11. Should interval/delayed LC vs. no additional treatment be used for patients previously treated by percutaneous cholecystostomy?

12. Should conversion of laparoscopic to open cholecystectomy vs. no conversion be used for limiting the risk or severity of BDI in the difficult laparoscopic cholecystectomy?

13. Should a time out to verify the CVS vs. no time out be used for limiting the risk or severity of BDI?

14. Should two vs. one surgeon(s) be used for limiting the risk or severity of BDI?

15. Should CVS coaching of surgeon vs. no coaching be used for limiting the risk or severity of BDI?

16. Should training by simulation or video-based education vs alternative surgeon training be used for limiting the risk or severity of BDI?

17. Should more vs less surgeon experience be used for mitigating the risk of BDI?

18. Should immediate reconstruction by the operating surgeon vs referral to a specialty center be used for patients with BDI during cholecystectomy?

these may underestimate the actual incidence due to limitations in using coding data to capture these injuries. Regardless, a $0.3 \%$ incidence of major BDI translates to between 2300 and 3000 BDI's annually in the USA alone. Biliary injury today is not just a phenomenon of LC but also can occur after open or laparoscopic converted to open cholecystectomy $[14,15]$. Bile duct injuries are also a source of increased morbidity and costs to the healthcare system. They can result in numerous re-interventions and hospitalizations, early and late complications, increased mortality, and poorer quality of life $[8,10,16-18]$. In one study, long-term mortality was $>8.8$-fold above the expected and age adjusted rate of death [19]. BDIs also remain one of the most common causes for litigation against general surgeons [20-23].

In this context in 2014, the Society of Gastrointestinal and Endoscopic Surgeons (SAGES) formed the Safe Cholecystectomy Task Force with the mission of creating a universal culture of safety around this operation and reducing 
biliary injuries. As an initial step, this group undertook a Delphi consensus process on strategies to reduce biliary injuries [24] and held subsequent collaborative meeting programming with other surgical societies. In 2016, planning began for a multi-society consensus conference on prevention of bile duct injury during cholecystectomy, that included SAGES, the Americas Hepato-PancreatoBiliary Association (AHPBA), the International HepatoPancreato-Biliary Association (IHPBA), the Society for Surgery of the Alimentary Tract (SSAT), and the European Association for Endoscopic Surgery (EAES). The process led to the development of a series of key questions to be addressed by comprehensive literature review, formulation of recommendations based on the evidence, and convening of a consensus meeting in Boston in October 2018 with expert and audience voting panels. The results of this process and recommendations from the consensus meeting form the basis of this guideline document.

\section{Guideline scope, purpose, and methods}

The aims of the consensus meeting were to identify optimal strategies for the prevention of bile duct injury during cholecystectomy and to develop and disseminate evidencebased practice recommendations for safe cholecystectomy. The guideline takes the surgeon-patient perspective. Topics covered include anatomic identification techniques, disease factors, surgical techniques, surgeon education, and intraoperative management of injury. Intended users of the guideline are general surgeons, hepatobiliary surgeons, and surgical trainees. It is anticipated that use of the guideline will help minimize the variability in surgical care for patients undergoing cholecystectomy, reduce the risk of BDI, and improve associated morbidity, cost, and quality of life. This guideline should also directly inform efforts by surgical training programs, hospitals, and professional associations to create and disseminate interventions to enhance patient safety in cholecystectomy and improve patient outcomes.

Detailed in Online Appendix 1 (http://links.lww.com/ SLA/B986) and summarized in Table 1 [25-34], the overall guideline development process was guided by SAGES policies and procedures for guideline development to meet recommendations for trustworthy guidelines by the Institute of Medicine (now the National Academy of Medicine) and the Guidelines International Network [35-38].

\section{Results of literature screening}

A total of 2798 records were identified (Fig. 1). Following screening for eligibility, 451 records (representing unique studies) were included for potential data extraction and assessment of risk of bias. However, 297 studies either incompletely reported outcome data or had poor face validity, obviating detailed data extraction (see Online Appendix 5, http://links.lww.com/SLA/B990). Finally, 154 studies informed this guideline.

\section{Guideline recommendations}

Question 1 Should the critical view of safety (CVS) versus other techniques (e.g., infundibular, top down, or intraoperative cholangiography) be used to mitigate the risk of bile duct injury during laparoscopic cholecystectomy?

Recommendation In patients undergoing laparoscopic cholecystectomy, we suggest that surgeons use the critical view of safety (CVS) for anatomic identification of the cystic duct and artery (expert opinion).

Summary of evidence No direct comparative evidence was identified to support the critical view of safety (CVS) over other methods for anatomic identification. The evidence for intraoperative cholangiogram (IOC) vs. no IOC is addressed under guideline question 4 . Restricting the meta-analysis to single arm cohort studies of sample size $\geq 400$ cases, the pooled incidence of BDI was 2 in one million cases when CVS was used ( $n=4$ studies with $n=5446$ cases) [39-42] versus a pooled BDI incidence of 1.5 in 1000 cases when the infundibular technique was used $(\mathrm{n}=3$ studies with 10,060 cases). [43-45] This comparison, however, was deemed high risk of bias by the GDG because of concerns regarding exchangeability of populations between the two intervention groups.

Narrative synthesis Forty-five full-text articles identified by the search methodology were reviewed that included three systematic reviews.

Use of critical view of safety The use of the critical view of safety (CVS) is based on two lines of indirect evidence. First, several large single institutional studies with a sufficient number of cases to potentially encounter BDI report lower than expected rates of BDI with routine use of the CVS $[39,41,42,46]$. In addition, as noted above in the summary of evidence, the pooled BDI incidence from studies reporting use of the CVS is lower than that from studies that 
describe identification primarily by what would be considered an infundibular approach [39-45, 47-49].

A second line of indirect evidence for use of the CVS comes from case series of BDIs that have analyzed the circumstances of the injury which have demonstrated that BDIs usually occurred in cases when the CVS was not attained. An analysis of the operative reports from 528 BDI cases (396 excluding cystic duct leaks, 479 laparoscopic cases) treated at a single institution in Amsterdam found documentation of the CVS in only 33 cases (6.3\%) [50]. Similarly, an examination of operative reports from 21 patients with BDI identified the infundibular method in all cases [51]. One study that reviewed 65 videos of laparoscopic cholecystectomy with complications found that videos from 11 BDI cases had not achieved the CVS while a control group without complications after LC 72\% had achieved the CVS [52].

The ability to achieve the CVS in $85-95 \%$ of attempted cases indicates that it is implementable [39-41]. Moreover, there is no substantial evidence that reasonable efforts to achieve the CVS have been associated with undesirable effects. The literature search identified only one report of BDI occurring during an attempt to achieve the CVS [53].

A systematic review (R-AMSTAR score [25] 23/44) of methods for intraoperative assessment of biliary anatomy for prevention of BDI included four studies on the CVS with 4593 patients [54]. One retrospective study compared patients undergoing laparoscopic cholecystectomy by the infundibular approach to those using the CVS [55]. While no BDIs occurred, the study was seriously underpowered to assess BDI as an outcome metric. It was also critically flawed in that it assumed a particular method was used for identification based on the experience of the surgeon without objective documentation of the actual method used.

Use of fundus-first dissection Use of the "fundus-first" or "top-down" method for intraoperative anatomic identification during laparoscopic cholecystectomy was examined in a review (R-AMSTAR score 18/44) of operative techniques during operations that were considered difficult based on conversion rate or iatrogenic complications (without specification of BDI occurrence) [56]. Eleven studies with a total of 1100 patients from 1995 to 2009 were reported. The authors did not detail the studies reviewed, but concluded that there was evidence for the safety and efficacy of this technique. The 11 studies referenced in this review were individually re-examined in full-text format [46, 57-66].

The selection criteria for patients undergoing laparoscopic fundus-first cholecystectomy were heterogeneous. Nine studies with a total of 934 patients reported no bile duct injury [57-62, 64-66]. However, in the largest series of 500 patients, the operative technique involved identification and tape ligation of the cystic duct prior to fundus-first dissection of the gallbladder [58]. When reported, conversion to open cholecystectomy occurred in 16 of $312(5.1 \%)$ cases and complications in 10 of 285 (3.5\%) cases. One additional single-center study, not included in the review described, reported no complications among 81 patients undergoing laparoscopic fundus-first dissection performed after the cystic duct was clipped and the cystic artery divided [67].

A prospective trial evaluated patients with contracted gallbladders as determined by preoperative sonographic criteria [68]. Patients were randomized by alternate numbers to either conventional laparoscopic cholecystectomy or to laparoscopic fundus-first dissection. Ten patients were excluded and two additional patients were added based on intraoperative finding of a contracted gallbladder. Among the 31 patients undergoing standard laparoscopic cholecystectomy, there were 10 conversions, 7 with complications, and 2 with BDI. There were no conversions or BDIs among the 33 patients undergoing fundus-first operations and one patient had a complication.

Two case series of BDIs discuss potential implications of a fundus-first gallbladder dissection. A series of 182 BDIs (30 during laparoscopic cholecystectomy) from four university hospitals in China noted that all BDIs occurred when dissection commenced in the region of the hepatocystic triangle [69]. Thus, dissection from the fundus was considered the optimal choice during cholecystectomy. On the other hand, a series of 8 devastating vasculo-biliary injuries found that all occurred with a fundus-first dissection after conversion of laparoscopic operation for severely inflamed gallbladders [70].

Justification Given the available evidence, the GDG relied on expert opinion to make this recommendation. Although studies were not designed to directly answer the effectiveness of the CVS, the anticipated effect would have been large. Event analysis of BDIs implicates methods of anatomic identification other than the CVS as potential causes of injury in essentially all cases evaluated. CVS is attainable in a majority of cases when attempted routinely. The safe extent of dissection in any case must always be tempered by surgical judgment, but there is no evidence that reasonable efforts to achieve the CVS have been harmful, and, therefore, use of CVS is logical. When operative conditions are difficult, and the CVS cannot be reasonably achieved, alternative methods for either anatomic definition or conclusion of the operation are critical to prevention of BDI or other injury.

Question 2 Should the fundus-first (top down) technique versus subtotal cholecystectomy be used to mitigate the risk of bile duct injury when the CVS cannot be achieved during laparoscopic cholecystectomy?

Recommendation When the critical view of safety cannot be achieved and the biliary anatomy cannot be clearly defined by other methods (e.g., imaging) during laparoscopic 
cholecystectomy, we suggest that surgeons consider subtotal cholecystectomy over total cholecystectomy by the fundusfirst (top down) approach (expert opinion).

Summary of evidence No direct comparative evidence addressed this key question. A number of non-comparative case series report low BDI risk with the application of both these techniques. An indirect comparison of this evidence was not considered appropriate by the GDG because the majority of non-comparative studies were underpowered, and the comparison was flawed due to confounding by surgical expertise, patient population selection, and subjectivity in the judgment of severity of inflammation. One study implicated the top-down approach under difficult conditions as a risk factor for BDI and vascular injury [70].

Narrative synthesis Thirty-five full-text articles identified by the search methodology are summarized below. Data regarding use of laparoscopic fundus-first dissection has been summarized in the section on Question \#1.

\section{Laparoscopic subtotal cholecystectomy}

Reviews and observational cohort studies Three reviews provide generalized information about the outcomes of laparoscopic subtotal cholecystectomy. A systematic review and meta-analysis of 30 studies of subtotal cholecystectomy for difficult gallbladders included 898 laparoscopic operations, 99 laparoscopic operations converted to open, and 234 primary open operations [71]. One BDI was reported $(0.08 \%)$. Subgroup analysis of 471 completed laparoscopic cases found bile leaks in 149, retained stones in 8, morbidity in 9, and one mortality. A review of 28 studies of 1280 patients undergoing subtotal cholecystectomy included 154 laparoscopic subtotal cholecystectomies [72]. Conversion occurred in 13 of 95 reported cases; there was no detailed information on BDI or other complications. A review of operative techniques in difficult cholecystectomy included 12 studies with 822 patients having laparoscopic subtotal cholecystectomy [56]. The authors stated that there was evidence for the safety and efficacy of this technique.

Full-text review of articles cited in the above reviews was performed and the following outcomes for laparoscopic subtotal cholecystectomy were tabulated: BDI, 1/657 (0.15\%); conversion 22/637 (3.5\%); morbidity 164/637 (25.7\%); mortality $2 / 637(0.3 \%)$; bile leak $161 / 580(27.8 \%)$; retained stones 14/458 (3.1\%) [44, 45, 63, 73-80]. Six additional cohort studies of laparoscopic subtotal cholecystectomy that were unique to those cited in the reviews were identified and included 796 patients with the following outcomes reported: BDI 1/370 (0.2\%); conversion 96/778 (12.3\%); morbidity 45/340 (13.2\%); mortality 0/575; bile leak 26/301 (8.6\%). [46, 81-85].

Comparative studies No studies directly compared laparoscopic subtotal cholecystectomy and fundus-first dissection as separate and distinct operations. However, laparoscopic subtotal cholecystectomy has been compared to operative alternatives in several formats.

Laparoscopic subtotal cholecystectomy vs. laparoscopic total cholecystectomy An analysis from the University Health System Consortium database compared outcomes of 487 patients undergoing laparoscopic subtotal cholecystectomy to laparoscopic total cholecystectomy [86]. A 1:1 propensity score match was used to account for differences in clinical and demographic factors. After matching, there were no differences in hospital length of stay (LOS), readmission rates, or mortality, but subtotal operations had higher total direct costs. BDI was not specified. A prospective, non-randomized trial compared results between patients with preoperative predictors for difficult cholecystectomy based on an objective scoring system [87]. Sixty-five patients who underwent a version of subtotal laparoscopic cholecystectomy had no BDI and one conversion. Sixty patients with standard total laparoscopic cholecystectomy incurred 2 BDIs $(p=0.134)$ and 6 conversions $(p=0.04)$.

Laparoscopic subtotal cholecystectomy vs. converted or primary open subtotal cholecystectomy In a meta-analysis of operations for difficult gallbladders, laparoscopic subtotal cholecystectomy compared favorably to open subtotal cholecystectomy with less risk of sub-hepatic collection (OR 0.4, 95\% CI 0.2-0.9), retained stones (OR 0.5, 95\% CI 0.3-0.9), wound infection (OR 0.07, CI 0.04-0.2), reoperation (OR $0.5,95 \%$ CI $0.3-0.9$ ), and mortality (OR 0.2, 95\% CI 0.05-0.9), but was associated with more bile leaks (OR 5.3, 95\% CI 3.9-7.2) [71].

A retrospective cohort analysis of the Nationwide Inpatient Sample database of 10,872 "damage control" gallbladder operations that included laparoscopic and open subtotal cholecystectomy and "trocar cholecystostomy" [88]. There were 360 BDIs reported with a $13.6 \%$ morbidity rate and 7.4\% in-hospital mortality rate. Laparoscopic subtotal cholecystectomy was attempted in 5164 cases with 2204 cases converted $(42.7 \%)$. The specific number of BDIs in each cohort was not reported, but no statistical difference between converted and non-converted cases was observed $(p=0.159)$. A single health system comparison of laparoscopic subtotal cholecystectomy $(n=24)$ and primary open subtotal cholecystectomy $(n=41)$ found similar postoperative complications with no BDIs, but longer postoperative LOS for open procedures [82].

Laparoscopic and open subtotal cholecystectomy vs. total cholecystectomy A retrospective multi-center study from The Netherlands of 191 subtotal cholecystectomies reported 175 laparoscopic subtotals with 45 conversions (25.7\%) [85]. A subgroup of subtotal cholecystectomy patients (laparoscopic and converted) was compared to a contemporaneous group of 152 patients with converted total cholecystectomy. There was one BDI in each group. The subtotal cholecystectomy group had significantly higher rates for cystic duct leak (13\% 
vs. $2 \%$ ), biliary event recurrence ( $15 \%$ vs. $3 \%$ ), readmissions (18\% vs. $8 \%$ ), and re-interventions ( $34 \%$ vs. $18 \%)$. The converted total cholecystectomy group had significantly more frequent wound infections (17\% vs. 6\%) and increased LOS (median 5 vs. 4 days).

A single health system study reported a 2:1 propensity matched comparison of 130 patients with standard cholecystectomy to 65 patients with subtotal cholecystectomy (laparoscopic, converted and primary open) [82]. Subtotal operations were associated with significantly more surgical site infections, re-interventions, and longer LOS.

Justification The GDG reasoned that when inflammation prevents anatomic identification by the CVS or by imaging, avoiding dissection of ductal structures would have an anticipated large effect in reducing BDI. A subtotal cholecystectomy approach that does not enter the hepatocystic triangle was considered preferable to pursuit of total cholecystectomy under these circumstances. The GDG unanimously agreed that the terms "subtotal cholecystectomy" and "top down" are not mutually exclusive and, in fact, forms of subtotal cholecystectomy can be performed with a dissection that proceeds from the region of the fundus [82, 86]. Therefore, under challenging conditions, BDI risk can be minimized via either subtotal or top down cholecystectomy if dissection in the hepatocystic triangle is avoided.

Question 3 Should video documentation of the CVS (alone or in addition to operative notes) versus photo documentation (alone or in addition to operative notes) be used for limiting the risk or severity of BDI during laparoscopic cholecystectomy?

Recommendation No recommendation could be provided for this question due to a lack of agreement of the expert panel and concerns regarding feasibility, acceptability, and medico-legal considerations.

Summary of evidence No evidence was found that directly compared the impact of the various alternatives for CVS documentation requirements on outcomes of bile duct injury and other complications of surgery. Indirect evidence on the proxy outcome of the quality of documentation of CVS consisted of five observational studies with 368 patients [89-93]. Accurate documentation of the CVS by description in operative notes is poor [90-92]. Photographs of the CVS from two views have been superior to photographs with one view [93]. Intraoperative cholangiography was judged superior to single view photographs of the CVS for documentation of biliary anatomy [89]. Video documentation has been reported to be superior to operative notes $[92,93]$ and to CVS photographs with 2 views [90]. No correlation has been established with any clinical outcomes.
Justification Because direct evidence for BDI was not found, the GDG considered indirect linked evidence.

The GDG opined that surgeons should strive to obtain the CVS during laparoscopic cholecystectomy to minimize BDI risk (see recommendation to Question 1). The GDG felt that encouraging a more accurate method for documentation of the CVS might promote its wider use and enhance patient safety. The GDG agreed that the quality of CVS documentation, as judged by external independent assessors, is a relevant although uncertain proxy for BDI risk.

There was no consensus on this recommendation at the consensus conference. There was considerable discussion about medico-legal implications and push back from surgeons. Alternate wording that was considered included surgeons "be encouraged to document CVS by doublet photography or video." Another suggestion was that surgeons document in written reports how the anatomy was identified (since this is often omitted or unclear). The concept would not be to establish a mandate, but rather to increase over time use of doublet photography (or video documentation) in surgical practice. It was noted that the value of documentation as a teaching or quality assurance tool is evident and has previously been shown to improve the quality of healthcare delivered [94]. Ultimately, due to stakeholder concerns regarding acceptability, a recommendation was not made.

Question 4 Should intraoperative biliary imaging (e.g., intraoperative cholangiography, ultrasound) versus no intraoperative biliary imaging be used for mitigating the risk of bile duct injury during laparoscopic cholecystectomy?

Recommendation In patients with acute cholecystitis or a history of acute cholecystitis, we suggest the liberal use of intraoperative cholangiography during laparoscopic cholecystectomy to mitigate the risk of bile duct injury (conditional recommendation, very low certainty of evidence). Surgeons with appropriate experience and training may use laparoscopic ultrasound imaging as an alternative to IOC during laparoscopic cholecystectomy.

In patients with uncertainty of biliary anatomy or suspicion of bile duct injury during laparoscopic cholecystectomy, we recommend that surgeons use intraoperative biliary imaging (in particular intraoperative cholangiography) to mitigate the risk of bile duct injury (strong recommendation, very low certainty of evidence).

Given that the evidence for the benefit of IOC in elective non-acute cholecystectomy is inconclusive, no recommendation addressing this scenario could be made.

Summary of evidence Evidence comparing intraoperative cholangiography (IOC) versus no intraoperative biliary imaging was considered in panel deliberations. No conclusive evidence was found for other types of biliary imaging. 
Randomized controlled trial (RCT) evidence $(n=9)$ for IOC was too underpowered for meaningful synthesis. Pooled evidence from 14 studies $[8,9,95-106]$ that included 2.5 million patients demonstrated findings favoring IOC over no IOC in most of the studies providing adjusted estimates of effect, but the benefit was greatest in the subgroup analysis for patients with acute cholecystitis. For the subgroup of patients with intraoperatively suspected BDI, the use of IOC led to an almost threefold increase in the odds of recognition of BDI compared with non-use of IOC.

Narrative synthesis A systematic review of randomized trials that compared IOC to no IOC in patients undergoing cholecystectomy identified 8 studies (including one of open cholecystectomy) that met inclusion criteria (R-AMSTAR score 31.5) [107]. Only two major BDIs were identified in 1715 patients and there were two avulsion injuries of the cystic duct after IOC. Overall, the BDI rate was $0.2 \%$ and major BDI rate $0.1 \%$. One additional randomized trial of 371 patients had one BDI in each group and was similarly inconclusive [108]. Because BDI is an uncommon event, further randomized trials would need an estimated minimum of 4500 patients per arm to show a difference in outcomes regarding use of IOC or other interventions and would not be practical to perform [109].

The incidence of BDI during cholecystectomy with and without IOC was pooled from 14 large studies of mostly administrative data of 2,540,700 cholecystectomies [8, 9, 95-106]. The studies were at moderate to high risk of bias due to the nature of administrative coding data. Overall, the analysis showed a reduced incidence of BDI with the use of IOC (OR 0.78 [0.63-0.96], $p<0.0001$ ). When risk adjusted, a similar though slightly lesser effect was observed (OR 0.81, 0.62-1.07). A 1987-2001 study from the Swedish inpatient registry reported 613 BDIs in 152,776 cholecystectomies and showed a $34 \%$ risk reduction in 94,569 patients in whom IOC was performed (multivariate analysis OR 0.66, 95\% CI 0.54-0.79) [105]. The GallRiks National Swedish registry for gallstones surgery analyzed outcomes in 51,041 cholecystectomies from 2005 to 2010 [8]. A total of 74 BDIs, defined as any damage to the bile duct or biliary tree including bile leaks, were identified (1.5\%). The use of IOC or intent to use IOC was associated with a reduced risk of bile duct injury only in patients with acute cholecystitis (OR $0.44,95 \%$ CI $0.30-0.63$ ) or a history of acute cholecystitis (OR $0.59,95 \%$ CI $0.35-1.00$ ). No association between cholangiogram use and rate of BDI was found in patients who did not have acute cholecystitis or a history of acute cholecystitis (OR 1.06, 95\% CI 0.75-1.49).

The rate of intraoperative recognition of injury was assessed by meta-analysis of 8 studies that included 1256 BDI's and compared IOC vs no IOC $[13,96,98,100,102$, 110-112]. The use of IOC was associated with increased intraoperative recognition of BDI compared to no IOC (OR $2.92,95 \%$ CI $1.55-5.68, p=0.014$ ).

Ultrasound has not been evaluated as extensively as IOC. Two systematic reviews found that laparoscopic ultrasound (LUS) and IOC have similar success rates for visualization of the biliary anatomy [54, 113]. One retrospective cohort study found 11 BDIs in 594 cases without LUS vs 0 in 248 cases with LUS $(p=0.04)$ [114]. A prospective multi-center cohort study reported no BDI and only three bile leaks in 1381 patients [115]. These studies do not directly address LUS vs IOC and the incidence of BDI but do suggest that ultrasound in experienced hands has excellent results in delineating biliary anatomy.

Justification Pooled evidence from 14 studies of $>2.5$ million patients demonstrated findings favoring IOC over no IOC in most studies reporting adjusted risk estimates, but the benefit was greatest in patients with acute cholecystitis. The GDG also deliberated on the alternative approach of using laparoscopic ultrasound imaging. No evidence was found to support or refute its use. In trained hands, ultrasound may be an appropriate alternative to IOC.

Multiple studies have shown that IOC is associated with a higher rate of intraoperative recognition of BDI. Although the certainty of evidence is very low, this is a consistent finding across studies. The GDG concluded that the subgroup of patients with uncertain anatomy or strong intraoperative suspicion of BDI will have a significantly higher baseline risk of BDI as well as at a higher risk for life-threatening complications of undetected/unrepaired BDI. For this subgroup of patients, the GDG invoked one the five paradigmatic GRADE scenarios Life-threatening Situation for strong recommendations based on "low or very low certainty evidence" [34]. The potential benefit of IOC is early recognition and avoidance of potentially increasing the severity of BDI. This benefit includes avoidance of excision of a portion of the bile duct and a higher level of injury which is often more difficult to repair and reconstruct.

Question 5A Should intraoperative near-infrared (NIR) biliary imaging versus intraoperative cholangiogram (IOC) be used for limiting the risk or severity of bile duct injury during laparoscopic cholecystectomy?

Recommendation No recommendation was made as current evidence comparing near-infrared cholangiography for identification of biliary anatomy during cholecystectomy to intraoperative cholangiography is insufficient.

Summary of evidence There was no direct evidence available for BDI or other outcomes for NIR vs IOC. The outcomes for ductal visualization were considered indirect evidence for BDI. Four observational studies provided data for the surrogate outcomes of visualization of cystic duct, 
common bile duct, and hepatic duct [116-119]. Pooling of the data for visualization of each structure yielded inconsistent findings: RR for cystic duct (CD) visualization was 1.1 (95\% CI 1.00-1.35; 4 studies; total patients $=430)$. RR for common bile duct (CBD) was 1.0 (95\% CI 0.97-1.03; 4 studies; total patients $=430$ ). RR for common hepatic duct was 0.76 (95\% CI 0.58-1.01, 4 studies; total patients $=300$ ), $p=\mathrm{NS}[120]$.

Narrative synthesis In the systematic review of mostly prospective cohort studies by Vlek et al. [120] (R-AMSTAR-29), 19 studies were reviewed and data pooled from four observational studies for surrogate identification of the cystic duct, common bile duct and common hepatic duct as shown above. Most of the studies reviewed were highly subject to bias and did not compare ICG visualization to white light. There was considerable heterogeneity in the populations studied. For example, both complicated and uncomplicated gallstone diseases were pooled and there were different definitions of complicated disease within the studies.

A review by Pesce et al. (R-AMSTAR-27) [121] analyzed 16 studies involving ICG in both laparoscopic and robotic cholecystectomies. Detection rates of the biliary anatomy in 590 pooled patients were as follows: cystic duct- $96.2 \%$ (94.7-97.7\%); common hepatic duct-78.1\% (74.8-81.4\%); cystic duct-common hepatic duct junction-72.0\% (69.0-75.0\%); and common bile duct-86.0\% (83.3-88.8\%). No comparison was done with IOC or white light.

Question 5B Should intraoperative near-infrared biliary imaging with white light versus white light biliary imaging alone be used for limiting the risk or severity of bile duct injury during laparoscopic cholecystectomy?

Recommendation We suggest that the use of near-infrared imaging may be considered as an adjunct to white light alone for identification of biliary anatomy during cholecystectomy (conditional recommendation, very low certainty of evidence). The GDG noted that relying on near-infrared imaging must not be a substitute for good dissection and identification technique (expert opinion).

Summary of evidence There was no direct evidence for BDI or other decision-making outcomes. One RCT $(N=640)$ demonstrated findings favoring NIR for the visualization of various ductal structures (cystic duct, common hepatic duct and the CBD) pre and post-dissection. These were considered proxy evidence for BDI.

Narrative synthesis: The results of a single-blind multicenter, randomized controlled trial of NIR and white light $(N=321)$ to white light alone $(N=318)$ were not available prior to the consensus conference but has recently been published [122]. The trial compared detection rates of seven biliary structures: cystic duct (CD), right hepatic duct (RHD), common hepatic duct (CHD), and common bile duct (CBD), cystic-common bile duct junction (CCBDJ), cysticgallbladder junction (CGJ), and accessory ducts (AD). Detection rates were statistically and significantly higher for the NIR group for each structure before dissection: OR ranges from 2.3 (95\% CI 1.6-3.2) for the CGJ to 3.6 (95\% CI 1.6-9.3) for the RHD. After dissection, similar differences were observed for all structures except the CD and CGJ, which were not significantly different.

Factors that affected detection rates were also assessed and body mass index (BMI), level of inflammation, patient age, and surgeon experience were found to be significant. Overall, BMI reduced visualization by $6 \%$ per BMI unit increase; however, visualization remained better with NIR compared to white light. The detection rate was approximately $40-70 \%$ less among patients with moderate-tosevere versus minimal inflammation. Every increased year of patient age reduced detection of the RHD and CHD by $4 \%$ and $2 \%$ after dissection, and the CGJ by $1 \%$ both before and after dissection. Surgeon experience in years was directly proportional to detection rates as well. There were two "mild" BDIs out of 639 patients, both in the white light only group and resulted in conversion to open operation $(p=0.25)$. A limitation of the study is that surgeons were not blinded to the method of imaging and anatomic structure detection. Of note, a 2nd randomized trial comparing NIR to white light is currently underway (FALCON trial, NCT 02558556).

Justification The one RCT ( $N=640$ patients) demonstrated findings favoring NIR for the visualization of various ductal structures (cystic duct, common hepatic duct and the CBD) pre- and post-dissection. The risk of bias was rated as serious due to outcome ascertainment bias as the surgeons were non-blinded. The indirectness of the findings was rated very serious because of concerns about generalizability of the findings to general surgical practice as well as concerns about the surrogacy of ductal visualization for BDI. Importantly, the GDG noted that relying on NIR must not be a substitute for good dissection and identification technique.

Recommendations for future studies Near-infrared cholangiography should be assessed in large trials compared to white light alone and to IOC with risk stratification and risk adjustment. Because BDI is unlikely to be captured in such trials, we additionally suggest these trials focus on proxy outcomes such as visualization of ductal structures, ability to obtain the critical view of safety, and complications including conversion to open cholecystectomy. In particular, this technology should be studied in difficult cholecystectomy patient populations that include those with acute 
cholecystitis or a history of acute cholecystitis, severe chronic cholecystitis, and obese patients.

Question 6 Should surgical (complexity) risk stratification versus alternative or no risk stratification be used for mitigating the risk of BDI associated with laparoscopic cholecystectomy?

\section{Recommendations}

A1 For patients with acute cholecystitis, we suggest that surgeons may use the Tokyo Guidelines 18 (TG18), AAST classification, or another effective risk stratification model for grading for severity of cholecystitis and for patient management (expert opinion).

A2 During operative planning of laparoscopic cholecystectomy and intraoperative decision-making, we suggest that surgeons consider factors that potentially increase the difficulty of laparoscopic cholecystectomy such as male gender, increased age, chronic cholecystitis, obesity, liver cirrhosis, adhesions from previous abdominal surgery, emergency cholecystectomy, cystic duct stones, enlarged liver, cancer of gallbladder and/or biliary tract, anatomic variation, bilio-digestive fistula, and limited surgical experience (expert opinion).

Summary of evidence No articles directly compared the incidence of BDI when a risk stratification system was used vs. when a risk stratification system was not used. There are many prognostic risk association studies, but these do not evaluate the effectiveness of using this prognostic information to alter management and mitigate the risk of BDI. There is, however, evidence to indicate that the presence of acute cholecystitis increases the risk of mortality as well as BDI. In addition, grading/risk stratification systems for the severity of acute cholecystitis exist, including the Tokyo Guidelines (TG) 2013 and 2018 [94, 123, 124] and the American Association of Surgery for Trauma (AAST) severity grading [125]. Furthermore, there is evidence that the risk of BDI increases with the severity of inflammation as proposed by the TG 13/18.

Narrative synthesis The association between TG13 severity of cholecystitis and BDI was best demonstrated in a 2016 a case-control study by Tornqvist et al. [126]. In this study, the TG13 risk stratification model was applied retrospectively to 158 patients who suffered a BDI during laparoscopic cholecystectomy and 623 matched controls who underwent laparoscopic cholecystectomy without BDI. The odds of BDI doubled among patients with acute cholecystitis (OR 1.97 95\% CI 1.05-3.72) and the risk increased as the grade of inflammation increased. When compared to no cholecystitis, the odds of BDI increased from 0.96 (95\% CI $0.41-2.25$ ) in Tokyo grade I cholecystitis, to 2.41 (95\% CI
$1.21-4.80)$ in grade II, and 8.43 (95\% CI 0.97-72.9) in grade III compared to no cholecystitis. The mortality was also increased with grade from $5.4 \%$ for grade III, $0.8 \%$ for grade II, and $1.2 \%$ for grade I cholecystitis (not risk adjusted).

The TG are currently the only risk stratification model that risk stratifies and guides management of patients with acute cholecystitis based on the severity grade. Controversy does exist regarding the validity of the Tokyo guidelines. A study by Hernandez et al. compared the AAST vs. TG13 severity grading systems for predicting postoperative outcomes in patients with acute cholecystitis and showed that the AAST criteria had better area under the curve (AUC) for predicting mortality (AUC 0.86 vs. 0.73 ), complications (AUC 0.76 vs. 0.63 ), and need for cholecystostomy tubes (AUC 0.80 vs. 0.68 ), all $p<0.05$ [125]. Another study demonstrated that TG13 missed $35 \%$ of patients with gangrenous/acute cholecystitis on final pathology [127].

A systematic review of factors that make laparoscopic cholecystectomy difficult [56] included 91 articles with 3 meta-analyses of randomized trials, 5 controlled randomized trials, 8 well-designed controlled studies, 13 well-designed experimental studies, and 63 descriptive retrospective studies. There was a total of 324,553 patients. Factors associated with difficult laparoscopic cholecystectomy included male gender, increased age, acute cholecystitis, chronic cholecystitis, obesity, liver cirrhosis, adhesions from previous abdominal surgery, emergency cholecystectomy, cystic duct stone, large liver, big gallbladder, cancer of the gallbladder and/or biliary tract, anatomic variation, bilio-digestive fistula, and surgeon experience. The association of these risk factors with BDI was not specifically examined.

Justification No evidence was found to support evidencebased recommendations. The GDG suggestions were, therefore, based on existing evidence of association. Given that risk stratification models demonstrate an association of more severe acute cholecystitis with higher rates of BDI, and complications and given the minimal risk of using these models, the GDG felt that guiding surgical intervention based on risk assessment could potentially mitigate the risk and severity of BDI.

Question 7 Should risk stratification that accounts for cholecystolithiasis versus no/alternate risk stratification be used for mitigating the risk of BDI associated with laparoscopic cholecystectomy?

Recommendation No recommendation was made as no risk prediction models exist that incorporate the presence or absence of gallstones as a factor that increases bile duct injury or difficulty of laparoscopic cholecystectomy.

No studies were identified that addressed this question specifically as regards to the primary outcome of bile duct 
injury or secondary outcomes of conversion, complications, or mortality, or proxy outcome of quality of the critical view of safety.

Question 8 Should immediate cholecystectomy defined as performed within $72 \mathrm{~h}$ of symptom onset be used in acute cholecystitis (AC) versus delayed cholecystectomy? Delayed cholecystectomy is defined either as: (a) between $72 \mathrm{hrs}$ and 10 days after symptom onset; (b) 6-12 weeks after symptom onset; (c) greater than 12 weeks after symptom onset.

Recommendation In patients presenting with mild acute cholecystitis (according to Tokyo Guidelines), we suggest surgeons perform laparoscopic cholecystectomy within $72 \mathrm{~h}$ of symptom onset (conditional recommendation, very low certainty of evidence). For patients with moderate and severe cholecystitis there is insufficient evidence to make a recommendation, particularly as it relates to the outcome of bile duct injury.

Summary of evidence Data were analyzed from a systematic review that consisted of 14 randomized trials [128] and one large population study [129]. The included randomized studies did not include AC severity grading raising the possibility that the subgroup of patients with moderate and severe cholecystitis were underrepresented. Another large population study showed that grading of severity was critically important in evaluating the rate of bile duct injury in cholecystectomy for acute cholecystitis [126]. In that study, patients with AC had a significantly higher BDI rate than patients without AC primarily due to a higher BDI risk in patients with moderate cholecystitis (TG Grade 2) RR 0.53 (95\% CI 0.31 to 0.90). Patients with mild AC (TG Grade 1) did not have a higher incidence of BDI. In severe $A C$ (TG Grade 3) there was a non-significant trend toward an increased rate of injury. In patients who had one or more prior attacks there was a significantly higher incidence of BDI. Also, there is concern that the existing evidence may be limited in its generalizability by the fact that there is variability in how the diagnosis of acute cholecystitis is made, and there is reason to be concerned that the administrative diagnostic codes may have included patients with acute biliary pain but no acute inflammation.

Narrative synthesis The effect of the timing of cholecystectomy in patients with AC on the occurrence of BDI and other outcomes has been the subject of multiple studies that consist of 18 randomized controlled trials, more than 70 observational trials, 8 meta-analyses of randomized controlled trials, and a systematic review of the meta-analyses. Of the 8 meta-analyses reviewed, the one by Cao et al. [128] (R-AMSTAR score 33/44) was selected for inclusion on the basis that it was recent, included almost all pertinent randomized controlled trials (14 in all), and the authors provided unpublished explanatory information. Of the multiple non-randomized studies evaluated, only the population-based propensity score-matched study by de Mestral et al. [129] was included. Several other timing studies not included in the GRADE analysis are discussed in Online Appendix 7 (http://links.lww.com/SLA/B992) [130-134].

Serious methodological problems in regard to standardization and other issues resulted in a low level of certainty in regard to conclusions. Awareness of these methodologic pitfalls is essential to interpretation of results and conclusions and to guide future studies. These include:

\section{Underpowering due to very low incidence variables}

A study adequately powered to detect a threefold drop in BDI from $0.3 \%$ to $0.1 \%$ at a $95 \%$ confidence limit would require 9000 patients, which is about 5 times more patients than are present in the largest available meta-analysis of RCTs. Mortality is a similarly affected variable. Only population-based studies containing many thousands of patients are likely to have the number of events required to study a problem with such a low event rate.

\section{Failure to demonstrate parity in pre-existing health status between early and delayed groups}

Age, weight, and comorbidities can influence outcomes in patients undergoing cholecystectomy. These and other potential confounders have a potential biasing effect and are in need of parity in comparative studies. For instance, in a recent large population-based study, patients undergoing early cholecystectomy were younger, more frequently female, less likely to have biliary tract obstruction, and had a lower co-morbidity burden [129]. These biases may be correctable by propensity score matching as was done in this study.

\section{Questionable diagnosis of acute cholecystitis by diagnostic coding}

The Tokyo Guidelines (TG) established the first standard diagnostic criteria for AC consisting of one symptom, one sign, and a confirming radiologic finding - the TG Triad. The 2013 version (TG13) of these diagnostic criteria were validated by comparison to pathologic findings and found to have sensitivity and specificity of $91.2 \%$ and $96.9 \%$, respectively [135]. Many studies, especially observational studies use hospital discharge diagnosis of $\mathrm{AC}$, which is based on admission diagnosis, operative report diagnosis, and pathologic report diagnosis. Coding may not be accurate 
when the admission and operative diagnoses are $\mathrm{AC}$ and the pathologic diagnosis is not. The frequency of use of the standard diagnostic triad in studies of AC by our analysis was adequate in RCTs (18 studies, of which 13 were evaluable and 10 used the triad) [128] but inadequate in many observational studies [133] (of 45 evaluable studies, 22 used the triad).

\section{Inappropriate inclusion of cases done during the period of maximal inflammation in the "delayed" group}

The debate over early versus delayed cholecystectomy is a question of whether it is better to operate in an "early" acute inflammatory phase after onset of symptoms, or to operate in a "delayed" manner after the acute inflammation has lessened. Although there is not universal agreement on the time intervals covered by the two terms, there is agreement that there is an unfavorable intermediate period during which cholecystectomy is more difficult due to the predictable severity of inflammation. The span of this unfavorable intermediate period is at a minimum between 10 days and 4 weeks. Studies that refer to surgeries done during that unfavorable time as "delayed" are not waiting for acute inflammation to subside, i.e., they are not adequately "delayed" which biases the results in favor of early cholecystectomy.

\section{Failure to consider the relationship between severity of acute cholecystitis and bile duct injury}

Until recently, severity grade has not been considered in any timing studies [134]. Tornqvist et al. in 2016 [126] studied the relation between severity of $\mathrm{AC}$ and BDI at cholecystectomy using the 2013 Tokyo Guidelines (TG13) for diagnosis and severity grade of AC. The adjusted risk of BDI was doubled among patients with AC (OR 1.97, 95\% CI 1.05-3.72) compared to controls without AC. Patients with mild AC (TG13 Grade 1) had no increased risk of BDI (OR 0.96, 95\% CI 0.41-2.25), but patients with moderate AC (TG Grade 2) had more than twice the risk (OR 2.41, 95\% CI 1.21-4.80). Patients with severe AC (TG13 Grade 3) had a trend toward an even higher risk of AC (OR 8.43, 95\% CI 0.97-72.9), but the number of patients was small. Patients with a prior history of attack(s) of AC had a significantly higher incidence of BDI also. This finding is consistent with multiple reports that prior attacks of $\mathrm{AC}$ are a risk factor for difficult operative conditions [136, 137].

Failure to consider severity grade in timing studies may result in confounding by inclusion of a higher proportion of patients with moderate cholecystitis in the delayed group because of a tendency to avoid early cholecystectomy when it is perceived that there is marked local inflammation. Also, a tendency to select patients with mild cholecystitis may result in studies which do not reflect accurately the influence of moderate inflammation on BDI.

\section{Comparison of outcomes between early and delayed cholecystectomy}

Seven outcomes were selected for analysis with BDI as the major outcome of interest.

\section{Bile duct injury}

All meta-analyses of RCTs were underpowered. Therefore, the large, propensity score-matched population-based study of de Mestral et al. [129] from the Province of Ontario, Canada was selected for analysis. It reported on 7110 propensity matched pairs of early and delayed cholecystectomy patients who were matched by patient and surgeon characteristics. Early was defined as within 7 days of hospital admission and delayed was defined as delayed beyond the early time frame (interquartile range 4-12 weeks). After matching, BDI was significantly less common in the early group [OR 0.53 (95\% CI 0.31-0.90)]. The certainty of the evidence is very low as the diagnosis was made by diagnostic code and severity of inflammation was not considered. The lowest quartile of the delayed group was operated before 4 weeks in the intermediate period of least desirable inflammatory conditions.

\section{Mortality}

Mortality was evaluated in 8 RCTs in the meta-analysis of Cao et al. (total of 1293 patients) [128]. There were only two deaths, one in the early group and one in the late group. The relative risk was 1.03 (95\% CI 0.05 to $20.50, p=\mathrm{NS}$ ). The certainty of the evidence was very low. Severity was not graded, there was a low number of events, and there was a moderate risk of bias because most of the larger studies included in the meta-analysis were given a low $3 / 5$ score on the Jadad scale [128]. In one RCT by Gutt et al. [138] comprising 618 of 1608 patients in the meta-analysis, the delayed group was operated between 1 and 7 weeks after presentation. Consequently, there is the possibility that many patients in the delayed group of this large RCT were operated before 4 weeks, i.e., in the intermediate period of unfavorable inflammatory conditions. In the population-based study by de Mestral et al., the mortality rate in the early group was $0.46 \%$ and in the late group $0.64 \%$ [129]. The relative risk was 0.73 (95\% CI $0.47-1.15, p=0.21 \mathrm{NS})$. 


\section{Conversion to open cholecystectomy}

This variable was evaluated in 12 RCTs in the meta-analysis of Cao et al. [128] (total of 1452 patients). The conversion rate was $13.4 \%$ in the early group and $15.4 \%$ in the delayed group. The relative risk was 0.86 (95\% CI 0.65 to 1.13 ), $p=$ NS. The certainty of the evidence was also very low for this variable for the same reasons as above for mortality.

\section{Patients with complications}

Nine RCTs in the meta-analysis of Cao with 1276 patients were available for study [128]. Complications occurred in $15 \%$ of patients in the early group (92/625) and 30\% in the delayed group (192/643). The relative risk of the number of patients with complications in the early compared with the delayed group was 0.66 (95\% CI $0.42-1.03, p=0.07)$. In the 10 RCTs that reported total complications, there were 158 events in 630 patients in the early group and 273 events in 646 patients in the delayed group $(p=0.03)$. The certainty of the evidence was very low for this variable for the same reasons as above for mortality and conversion to open. There was also wide $\mathrm{CI}$ and suboptimal information size and results were inconsistent across trials included in the metaanalysis $\left[I^{2}=50.82, p=0.04\right]$.

\section{Duration of surgery}

Duration of surgery was reported for 1276 patients in 10 RCTs in the Cao meta-analysis [128]. The mean duration of surgery was 99 min in the early group which was slightly but not significantly longer than in the delayed group (86 min, $p=0.23)$. The certainty of the evidence was very low.

\section{Length of total hospitalization}

In the meta-analysis, there were 11 RCTs with 1383 patients related to this variable [128]. Mean total length of hospital stay was 4.1 days in the early group vs 7.3 days in the delayed group $(p<0.001)$. The certainty of the evidence was low as severity was not graded and there was moderate risk of bias. The large treatment effect raised the certainty of evidence one level.

\section{Wound infection}

In the meta-analysis of Cao et al. [128] wound infections were reported in 8 RCTs containing 1145 patients. In the early group, the incidence of wound infection was $4.2 \%$, and in the delayed group, it was $6.2 \%$. The relative risk in early and delayed groups was 0.57 [95\% CI 0.35-0.93, $p=0.02$ ].

\section{Re-presentation before scheduled delayed cholecystectomy}

In the meta-analysis, 4 RCTs reported on re-presentation in the delayed group after initial successful non-operative treatment [128]. Of patients treated non-operatively initially, $18.5 \%$ re-presented prior to having delayed cholecystectomy. Eight studies reported the need for urgent surgery prior to the scheduled date in the delayed group. Emergency laparoscopic cholecystectomy was needed earlier than the planned date in $9.7 \%$ of patients initially treated non-operatively.

Justification The evidence indicates that patients with mild AC do not have an increased rate of BDI whereas patients with moderate $\mathrm{AC}$ have double the incidence of BDI. However, because studies have not matched patient groups appropriately for the presence of moderate cholecystitis, it cannot be determined whether early or delayed cholecystectomy is superior in terms of the risk of BDI in that group of patients. Since BDI is the main outcome measure examined in the consensus conference and is a highly morbid, costly complication which necessitates invasive procedures and has a long-term effect on the quality of life of patients, it supersedes all other outcome measures in importance. Therefore, despite the superiority of early cholecystectomy in terms of total patient hospitalization, wound infection, and the need for unexpected care while waiting for cholecystectomy, the recommendation for early cholecystectomy can only be made in patients who have mild cholecystitis. The recommendation does not imply that delayed cholecystectomy is superior in patients with moderate severity AC. Further studies that incorporate the severity of the disease are needed to answer this question.

\section{Recommendations for future studies}

\section{Regarding the need to grade severity of $A C$ and history of prior attacks of $A C$}

Studies that examine the relationship between BDI and AC should match patients at baseline both for severity grade of $\mathrm{AC}$ and history of prior attacks of AC.

\section{Method of diagnosis of AC}

The diagnosis of AC should be documented in future studies following well-accepted clinical criteria such as TG18 diagnostic criteria, histologic findings of acute inflammation, or both. If documentation of AC is based on diagnostic codes such as ICD codes, investigators should ensure that the diagnostic codes confirm with the preceding criteria. 


\section{Regarding classification of timing of surgery in studies} of acute cholecystitis

In $\mathrm{AC}$, for the purposes of reporting standardization and ability to compare results among studies, we suggest that the interval between onset of symptoms and time of operation should be defined in 4 phases:

Phase 1 Onset of symptoms to $72 \mathrm{~h}$. Inflammation expected to be favorable for cholecystectomy. Tissue swelling due to edema.

Phase $272 \mathrm{~h}$ to 10 days. Inflammation expected to be less favorable for cholecystectomy. Due to tissue swelling and increased vascularity.

Phase 310 days to 6 weeks. Inflammation expected to be much less favorable for cholecystectomy. Acute and chronic inflammation.

Phase 46 weeks or later. Inflammation expected to be more favorable again for cholecystectomy. Predominately chronic inflammation.

There is also some justification for a period greater than 12 weeks but there is very little information in the literature that this time period had been the subject of study.

Question 9 Should subtotal cholecystectomy versus total laparoscopic or open cholecystectomy be used for mitigating the risk of BDI in marked acute inflammation or chronic biliary inflammatory fusion (BIF)?

Recommendation When marked acute local inflammation or chronic cholecystitis with biliary inflammatory fusion (BIF) of tissues/tissue contraction is encountered during laparoscopic cholecystectomy that prevent the safe identification of the cystic duct and artery, we suggest that surgeons perform subtotal cholecystectomy either laparoscopically or open depending on their skill set and comfort with the procedure (expert opinion).

Summary of evidence No direct comparative evidence was found addressing this question. Indirect qualitative comparisons from case series of subtotal cholecystectomy versus total cholecystectomy was considered critically flawed because of non-exchangeability of surgical populations due to confounding by indication for subtotal versus total cholecystectomy (see also discussion Question 2).

Narrative synthesis Only one article directly compared subtotal cholecystectomy (STC) to laparoscopic total cholecystectomy (LC) with bile duct injury (BDI) as an outcome metric [86]. This retrospective study used administrative data from the University HealthSystem Consortium Database to compare LC to STC. Patients who underwent laparoscopic subtotal cholecystectomy were older (56 vs 48 years), more likely male ( $54.2 \%$ vs $32.3 \%$ ), and had higher severity of illness scores on admission $(9.2 \%$ vs $3.5 \%)$ [ $p<0.001]$ compared to standard LC. On univariate analysis, patients who underwent STC experienced longer lengths of stay (4 vs 3 days), higher readmission rates (11.9 vs $7.0 \%$ ) and higher mortality $(0.82$ vs $0.28 \%)[p<0.05]$. Following a $1: 1$ propensity score match, no differences in outcomes were demonstrated between patient groups. Thus, the authors concluded that STC is a safe and feasible alternative to LC in well-selected patients. The strength of this conclusion is dampened by the retrospective nature of the study and confounding variables such as intraoperative details, surgeon factors and patient factors which were not accounted for.

Of the remaining articles assessed, none directly compared outcomes and focused on the safety and feasibility of each technique. A systematic review identified 30 studies of 1200 patients who underwent subtotal cholecystectomy [71]. BDI was the primary outcome measure with other complications as secondary outcomes. The approach was laparoscopic in $72.9 \%$, open in $19.0 \%$, and laparoscopic converted to open in $8.0 \%$. Reasons for cholecystectomy were $\mathrm{AC}$ in $72 \%$, cirrhosis/portal hypertension in $18.2 \%$, gangrene or perforation in $6.1 \%$, and Mirizzi syndrome in 3\%. BDI was reported in $0.08 \%$, bile leak in $18.0 \%$, sub-hepatic collections in $2.9 \%$, retained stones in $3.1 \%$ of patients, need for post-op ERCP in $4.1 \%$, and reoperation in $1.8 \%$. The mortality rate was $0.4 \%$. When outcomes of laparoscopic vs open subtotal cholecystectomy were compared, the laparoscopic approach was associated with less risk of sub-hepatic collection (OR 0.4, 95\% CI 0.2-0.9), retained stones (OR $0.5,95 \%$ CI $0.3-0.9$ ), wound infection (OR $0.07,95 \%$ CI $0.04-0.2$ ), reoperation (OR $0.595 \%$ CI 0.3-0.9), and mortality (OR $0.2,95 \%$ CI $0.05-0.9$ ), but had more bile leaks (OR 5.3, 95\% CI 3.9-7.2). Bile leaks resolved spontaneously in $31.2 \%$. Of note, there was no standardization of technique across the various studies for how subtotal cholecystectomy was performed and outcomes were not compared to total cholecystectomy.

Justification Because no admissible direct or indirect evidence addressed this guideline question, the panel deemed that a subtotal cholecystectomy is likely to limit the risk of BDI when operative conditions prevent clear anatomic identification by avoiding dissection in the hepatocystic triangle. Both open and laparoscopic approaches for subtotal cholecystectomy were considered relevant based on patient and surgeon factors.

Question 10 Should standard 4-port lap cholecystectomy versus reduced port laparoscopic cholecystectomy (single incision laparoscopic cholecystectomy, SILC) versus robotic cholecystectomy versus open cholecystectomy versus other techniques be used for limiting the risk or severity of bile duct injury in candidates for cholecystectomy? 
Recommendation For patients requiring cholecystectomy, we suggest using a multi-port laparoscopic technique instead of single port/single incision technique (conditional recommendation, moderate certainty of evidence).

Summary of evidence No direct comparative evidence addressed this outcome. Indirect comparison was made from evidence from two systematic reviews (including total $>507,918$ patients) of single arm cohort studies of single port versus standard port approach. The pooled effect estimate for BDI was $0.72 \%$ (simple average of the data across studies) vs. 0.32 to $0.52 \%$ (pooled range). The outcomes on which results favored single port laparoscopic cholecystectomy were analgesic use, cosmesis, and quality of life. The magnitude of these effects was imprecise as well as clinically small to trivial. The undesirable effects for single port laparoscopic cholecystectomy include BDI, total severe complication, operative time, port site hernia, and conversion to open procedure. The magnitude of these effects was conservatively judged moderate by the panel.

Narrative synthesis In a 2012 systematic review of BDI in SILC [139] (45 cohort studies, $n=2626$ ), a pooled rate of BDI with SILC of $0.72 \%$ was found, potentially representing a higher rate of BDI than reported in previously reported large-scale pooled data for 4-port LC $(0.32-0.52 \%)$ [11]. A 2018 meta-analysis of 24 randomized trials $(n=4518)$ comparing SILC to 4-port LC reported a significantly increased incidence of major complications (Clavien-Dindo grade III or greater) in SILC, $2.7 \%$ vs. 1.1\%, RR 2.02 (95\% CI 1.29-3.15) [140]. The quality of evidence in this review was moderate with good consistency of results.

Other outcomes were assessed by three smaller reviews, which were deemed of low or very low quality with high bias risk. Postoperative analgesia use was compared for SILC and 4-port LC in a 2013 review (2 cohort studies, 1 $\mathrm{RCT}, n=361)$. No difference was reported in postoperative opioid use, weighted mean difference $-3.78 \mathrm{mg}(-13.78$ to $6.22 \mathrm{mg}$ ) [141]. Conversion rates were compared for SILC and 4-port LC in a 2014 review (27 RCTs, $n=2049$ ), with no difference between groups ( $0.2 \%$ in both groups) [142]. A 2014 Cochrane review of 9 RCTs of 4-port vs. reduced port LC ( 7 trials assessed SILC; 2 trials 3-port LC) reported longer operative time for reduced port LC (mean difference +14.4 95\% CI 6.0-23.0 min) [143].

Justification Although for individual outcomes, the certainty ratings ranged from very low to moderate, the evidence on critical outcomes (BDI, severe complication) consistently favored standard port laparoscopic cholecystectomy with certainty rating for severe complications judged to be moderate. As such, the highest certainty evidence informed overall certainty. Although there may be variability in how much patients value cosmesis, the panel believes that almost all patients will value the remainder of outcomes greater than cosmesis alone. Although evidence favors standard port, the panel acknowledged that in highly experienced hands, single port may yield similar outcomes as standard port.

Question 11 Should interval laparoscopic cholecystectomy versus no additional treatment be used for patients previously treated by cholecystostomy drainage?

Recommendation In patients with acute calculous cholecystitis previously treated by cholecystostomy who are good surgical candidates, we suggest that interval cholecystectomy is preferred after the inflammation has subsided. For poor or borderline operative candidates, we suggest a nonsurgical approach that may include percutaneous stone clearance through the tube tract or tube removal and observation if the cystic duct is patent (expert opinion).

Summary of evidence No direct comparative evidence was found that addressed this question. Making indirect comparisons from case series of patients treated by cholecystostomy who had no additional treatment versus patients who had interval cholecystectomy was considered flawed because of non-exchangeability of the populations due to confounding in the predicted operative risks of the patients. Stated otherwise, in studies of this type, the group of patients who do not undergo interval cholecystectomy will be composed of patients who are candidates for surgery as well as patients who are not candidates for surgery in unknown proportions. Because such a group contains patients who are not candidates for cholecystectomy, they cannot be directly compared to a group of patients all of whom were considered to be candidates for surgery and underwent cholecystectomy. We found no studies in which this issue was addressed by propensity scoring or randomization of fit candidates for surgery to cholecystectomy or observation.

Narrative synthesis A systematic review on the use of cholecystostomy as a treatment for AC performed in 2007 identified 53 studies that included 1918 patients [144]. The short-term mortality after cholecystostomy tube placement, 30-day or in-hospital, depending on which was reported in the manuscripts, was $15.4 \%$. Thirty-eight percent of patients had an interval elective cholecystectomy and $4.5 \%$ required an emergent cholecystectomy. The operative mortality of patients undergoing elective interval cholecystectomy was $0.96 \%$ and mortality was $13 \%$ in patients undergoing emergent cholecystectomy. Emergent cholecystectomy included cholecystectomy during the index admission due to therapeutic failure and procedural complications in addition to patients experiencing recurrent cholecystitis after removal of the cholecystostomy tube.

A retrospective cohort study published in 2013, using a population-based administrative database from Canada, 
identified 890 patients who had a cholecystostomy tube placed for acute cholecystitis from 2004 to 2011 [145]. Inhospital mortality was $5 \%$. At 3 months, $25 \%$ of patients had a cholecystectomy and $10 \%$ had died without undergoing cholecystectomy. At 1 year, $40 \%$ had cholecystectomy and $18 \%$ had died. Thirty-day and 1-year postoperative mortality in the cholecystectomy group was $2 \%$ and $6 \%$, respectively. In the 866 cholecystostomy patients discharged without cholecystectomy, the risk of gallstone-related emergency department visit or hospitalization was $23 \%$ at 3 months and $49 \%$ at 1 year. In-hospital mortality of gallstone-related admissions was $1 \%$.

A single-center retrospective review from the USA identified 288 patients who had a cholecystostomy tube placed for acute calculous cholecystitis from 1997 to 2015 [146]. In-hospital mortality was $9 \%$. Tube dysfunction occurred in $46 \%$ of patients with $28 \%$ requiring re-intervention. Thirtysix percent of patients underwent subsequent elective cholecystectomy, and the rate of recurrent biliary events was $6.8 \%$ vs $21.1 \%$ in patients who did not have a cholecystectomy (5.8\% vs $18.5 \%$ at 1 year). The risk of biliary-related deaths in the patients who did not have a cholecystectomy was $5 \%$. A single-center retrospective review from Denmark identified 278 patients who had a cholecystostomy tube placed for acute calculous cholecystitis from 2002 to 2012 [147]. Thirty-day mortality was $4.7 \%$. Of 234 patients discharged, $23.5 \%$ were readmitted for recurrent cholecystitis, $54.7 \%$ were followed for a median of 5 years without recurrence, and $21.8 \%$ had an elective interval cholecystectomy. In another single-center retrospective review from the USA, 245 patients between 2009 and 2012 had a cholecystostomy tube placed [148]. Of the 202 patients who survived to discharge, $48 \%$ had calculous cholecystitis and $41 \%$ had acalculous cholecystitis. Seventy-one patients (35\%) were determined to be operative candidates, the majority of whom had calculous cholecystitis and had a planned interval cholecystectomy. Two smaller series of 93 and 68 patients reported recurrent gallbladder disease in $19 \%$ and $41 \%$, respectively, of patients who did not undergo planned interval cholecystectomy $[149,150]$.

In addition to a patient's surgical risk, the subgroups of patients with calculous and acalculous cholecystitis need to be considered. Some data in the literature demonstrates a lower risk of recurrent biliary symptoms after cholecystostomy tube removal in patients with acalculous cholecystitis. The largest study, with 88 patients, demonstrated a $2.7 \%$ risk of recurrence over an 8-year follow-up [151]. Smaller studies have demonstrated a 7-14\% risk of recurrence [152-154].

It should be noted that an important issue related to management of patients with a cholecystostomy tube is the indications for placement of a cholecystostomy tube. CHOCOLATE, a Dutch randomized trial that compared laparoscopic cholecystectomy to percutaneous cholecystostomy in high-risk patients with acute calculous cholecystitis was recently published [155]. The results from this study strongly favor laparoscopic cholecystectomy over cholecystostomy tube placement.

Justification In the available case series, the desirable anticipated effect of interval cholecystectomy is avoidance of recurrent gallbladder-related symptoms which occurred in $20-50 \%$ of patients who did not undergo interval cholecystectomy. There is also some evidence that in this group recurrent symptoms were associated with urgent cholecystectomy, which has a higher rate of open cholecystectomy and postoperative complications, whereas patients who undergo elective interval cholecystectomy are more likely to have the cholecystectomy completed laparoscopically with its associated benefits. The undesirable anticipated effect of interval cholecystectomy is increased cholecystectomyrelated complications including mortality. In the largest case series, the 30-day mortality after interval cholecystectomy was $2 \%$. However, this will vary significantly based on criteria used to select patients for elective interval cholecystectomy. The available data is retrospective and it is likely that the patients selected for elective interval cholecystectomy were chosen for their perceived ability to tolerate surgery. The guideline panel judged, therefore, that in the subgroup of patients determined to be fit for surgery, the balance of effects favors the intervention, and the anticipated desirable effects were determined to be moderately substantial. In the subgroup of patients determined to be unfit for surgery, the balance of effects probably favors the alternative management option.

Question 12 Should conversion of laparoscopic cholecystectomy to open cholecystectomy versus no conversion be used for limiting the risk or severity of bile duct injury during difficult laparoscopic cholecystectomy?

Recommendation No recommendation was made as the current evidence comparing conversion versus no conversion to open cholecystectomy to limit/avoid bile duct injury in the difficult cholecystectomy is insufficient.

Thirteen studies were reviewed but none fit within the criteria for this analysis. No evidence was found for the outcome BDI or any of its proxy outcomes.

Recommendations for future studies: (1) We suggest the conduct of prospective and retrospective comparisons of clinical outcomes of various 'bail-out' options for the difficult cholecystectomy that include conversion to open, subtotal cholecystectomy, and procedure abandonment. (2) We further suggest the development and establishment of valid evidence for a 'procedure difficulty score' for laparoscopic cholecystectomy and study of its effectiveness in limiting BDI risk. 
Question 13 Should surgeons take a time out to verify the critical view of safety versus no time out be used for limiting the risk or severity of bile duct injury during laparoscopic cholecystectomy?

Recommendation Current evidence is insufficient to make a recommendation. However, as a best practice, we suggest that during laparoscopic cholecystectomy, surgeons conduct a momentary pause for the surgeon to confirm in his/her own mind that the criteria for the critical view of safety have been attained before clipping or transecting ductal or arterial structures (expert opinion).

Of two studies reviewed, no evidence was found for the outcome BDI or any of its potential proxy outcomes [156, 157]. While no evidence exists to answer this question, the GDG panel felt based on experience that the incorporation of a momentary pause to verify the appropriateness of the CVS before any structures has the potential to decrease the risk of BDI. As the most common cause of BDI is a misperception of anatomy, the momentary pause is an opportunity to verify that what one is seeing is likely the correct anatomy. This practice should be easily implementable and without significant effort or delay required.

Recommendation for future studies We suggest incorporation of a "critical view momentary pause" in all prospective studies of laparoscopic cholecystectomy.

Question 14 Should two surgeons versus one surgeon be used for limiting the risk or severity of bile duct injury during laparoscopic cholecystectomy?

Recommendation No recommendation was made as the current evidence comparing two versus one surgeons for limiting/avoiding bile duct injury in cholecystectomy is insufficient.

A single study was identified from the literature search, but was excluded as it did not include evidence for the outcome BDI or any of its proxy outcomes [158]. Performing cholecystectomy with two surgeons present is not feasible in most settings. Given the potential beneficial effects of the presence of a second surgeon and the added experience that becomes available, the advice of a second surgeon is often very helpful under conditions in which the dissection is stalled, the anatomy is unclear, or under other conditions deemed "difficult" by the surgeon.

Retrospective assessment of case notes where the involvement of multiple surgeons was recorded should be possible from billing and electronic records, and linkage of these cases to outcomes could provide insight into the usefulness of two-surgeon cholecystectomy. The effect of access to and/ or involvement of subspecialist hepatobiliary surgeons and impact on outcomes should also be assessed. Prospective multi-center cohort studies are desirable to capture the effect of multiple surgeon involvement in clinical outcomes.

Question 15 Should critical view of safety coaching of surgeons versus no specific critical view of safety coaching be used for limiting the risk or severity of bile duct injury during laparoscopic cholecystectomy?

Recommendation We suggest as a best practice continued education of surgeons regarding the critical view of safety during laparoscopic cholecystectomy that may include coaching (conditional recommendation, very low certainty of evidence).

Summary of evidence Five studies were identified from the literature search for review. One study directly addressed this question but was not considered appropriate for inclusion due to numerous flaws (underpowered to detect BDIs, inclusion of bile leaks as BDIs, confounding by surgeon skill) [159]. Therefore, one before and after study which addressed the proxy outcome of quality of CVS was included. In a group of five practicing surgeons who received CVS coaching, their scores on the Strasberg scale improved significantly from 1.75 at baseline to 3.75 after training (very low certainty evidence because of study design and fragility of effect) [160].

The GDG agreed that there was evidence from other surgical domains in support of this judgment. A systematic review of quality of evidence for surgical coaching and its impact on outcomes reported a positive impact on surgical performance, with strong evidence particularly in the domain of technical skills [161]. A 2015 randomized trial reported significantly improved global and technical performance in porcine $\mathrm{LC}$ when comparing coaching to no coaching [162].

Justification Obtaining a high-quality "critical view" was considered paramount by the GDG to avoid BDI during laparoscopic cholecystectomy. Given that current evidence suggests that the majority of surgeons do not routinely obtain the CVS [160], and the benefits of education and coaching in improving performance and changing behavior demonstrated in several fields including surgery [161], the GDG felt that coaching should be employed to improve the quality of dissection and of the CVS and may lead to decreased risk of BDI.

Question 16 Should training of surgeons by simulation methods or video-based education versus alternative surgeon training be used for limiting the risk or severity of bile duct injury during laparoscopic cholecystectomy? 
Recommendation No recommendation was made as the current evidence comparing simulation or video-based training versus alternative surgeon training modalities on limiting/avoiding bile duct injury during laparoscopic cholecystectomy is insufficient.

Five studies were identified from the initial literature search [163-167]. No evidence was found for the outcome BDI or any of its proxy outcomes.

Recommendation for future studies We suggest the conduct of prospective large-scale multi-center studies to determine the role of simulation vs video-based vs alternative surgeon training modalities on limiting/avoiding BDI. More realistic simulators incorporating immersive virtual technology and advanced haptics should be considered for development, and their effectiveness studied.

Question 17 Should more surgeon experience versus less surgeon experience be used for mitigating the risk bile duct injury associated with laparoscopic cholecystectomy?

Recommendation We suggest that surgeons have a low threshold for calling for help from another surgeon when practical in difficult cases or when there is uncertain of anatomy (conditional recommendation, very low certainty of evidence).

Summary of evidence From 23 studies identified from the initial literature search, a single 2014 observational study was included which examined 53,632 LC's from a US billing database and linked surgeon codes to the Fundamentals of Laparoscopic Surgery (FLS) database [7]. The authors reported that more experienced surgeons (mean 20.7 vs. 6.1 years in practice) experienced a lower rate of BDI ( $0.14 \%$ vs. $0.47 \%, p=0.0013$, RR 0.27 [95\% CI $0.13-0.57]$ ) compared to less experienced surgeons.

Justification Despite the large effect size and effectively non-existent undesirable effects, a strong recommendation was not provided due to acceptability and feasibility considerations, especially in smaller community hospitals or rural areas (where only one surgeon may be available). The GDG felt that senior support could be sought for difficult cases identified pre- or intraoperatively, or that referral to more experienced centers should be considered where such support is not available.

Recommendation for future studies We suggest the conduct of prospective research studies to develop evidencebased guidelines and measure the impact of interventions (such as the SAGES Safe Cholecystectomy initiative) for physicians who are in transition in practice/from residency/fellowship to independent practice, in order to mitigate the risk of BDI associated with laparoscopic cholecystectomy.
Additional studies to measure the impact of surgeon experience on outcomes in LC are needed. Prospective comparisons of the effectiveness of the various BDI mitigating training methods on the laparoscopic cholecystectomy outcomes of early career surgeons should be considered.

Question 18 For patients with bile duct injury during laparoscopic cholecystectomy (in the OR or early postoperative period), should the patient be referred to a specialist with experience in biliary reconstruction or should the reconstruction be performed by the operating surgeon?

Recommendation When a bile duct injury (BDI) has occurred or is highly suspected at the time of cholecystectomy or in the postoperative period, we recommend that surgeons refer the patient promptly to a surgeon with experience in the management of BDI in an institution with a hepatobiliary disease multispecialty team. When not feasible to do so in a timely manner, prompt consultation with a surgeon experienced in the management of BDI should be considered (strong recommendation, low certainty of evidence).

Summary of evidence No randomized control trials or systematic reviews were found that addressed this question. There were three retrospective studies and 44 case series, the majority of which include only patients with BDI repaired at expert centers. Studies of BDI series that compared outcomes of repair by the primary surgeon/institution vs HPB centers were considered flawed because they consisted mostly of failed primary repairs and lack a denominator of total repairs by the primary surgeon. Seven observational studies summarized below that included a total of 1392 patients with BDI addressed this question and showed a large consistent effect across a number of outcomes (rates of cholangitis, bile leak, stricture, reoperation, other intervention, and death) that favored specialist surgeons over primary surgeons. The studies were judged to be at high risk of bias due to unclear comparability and an unknown degree of missing data. An umbrella systematic review of 32 systematic reviews covering 15 surgical procedures provided indirect evidence additionally favoring higher surgeon experience or volume (R-AMSTAR score 33/44) [168].

\section{Narrative synthesis}

1. Perera et al. [169] presented a series of 200 patients treated for major BDI with a median follow-up of 60 months. In $52 \%$ of the cases the anatomy was described as "straightforward" during the LC; $72 \%$ of the injuries were a major type E injury and $13 \%$ a type D. Of 157 patients managed surgically, 112 (71\%) underwent reconstruction by specialist HPB surgeons and 45 patients $(29 \%)$ were operated by non-HPB surgeons prior to referral. Multivariate analysis showed that 
on table repair done by non-specialist surgeons was an independent risk factors for recurrent cholangitis (33\% vs $11 \%$ ), biliary strictures ( $69 \%$ vs $17 \%$ ), redo reconstructions ( $53 \%$ vs $3 \%$ ), and overall morbidity ( $82 \%$ vs $25 \%), \mathrm{p}<0.001$.

2. Stewart et al. [170] reported outcomes in 137 patients with BDI repaired by HPB surgeons after no prior attempt at repair compared to 163 patients referred after repairs by the primary surgeon. The success rate of repair by HPB surgeons was $90.5 \%$ vs. $20.9 \%$ with primary surgeon repair.

3. $\mathrm{Xu}$ et al. [171] examined outcomes of repair of 77 patients with BDI across 15 provinces in China. The success rate of repair by HPB specialists in 42 patients was $83.3 \%$ compared to a success rate of $31.4 \%$ in 35 patients repaired by the primary surgeon.

4. DeReuver [172] in a study of 500 BDIs referred found on multivariate analysis that factors associated with failure included secondary referral after prior surgical, endoscopic, or radiologic interventions.

5. Sicklick et al. [173] reported a single institution retrospective analysis on 200 patients treated for major BDI. Eighty-one patients (44\%) had attempted repairs at outside institutions prior to referral. Only 15 of 89 repairs (17\%) required no further reoperation. In 31 patients (34.8\%), the original laparoscopic surgeon performed an end-to-end ductal anastomosis and in 18 patients $(22.5 \%)$ the surgeon was unable to repair the injury. Definitive repair at the specialty center with a Rouxen-Y hepatico-jejunostomy was carried out in $98 \%$ of patients. Complications occurred in $42.9 \%$ of patients but no patient required reoperation.

6. Thomson et al. [174] reported on 123 BDI, 87 (70.7\%) occurring during LC and 33 (26.8\%) during open cholecystectomy. Of 55 patients who had an attempted repair prior to referral, only 12 (22\%) required no further surgical intervention. Of the 42 patients who required further surgery, 27 had a failed primary ductal repair at the outside institution. A successful outcome of repair was achieved by a team experienced in the management of BDI in $89 \%$ of cases.

7. Rystedt et al. [175] reported results of early repair in 140 of 155 bile duct injuries detected during laparoscopic cholecystectomy, 90 of which were initially repaired by the index surgeon. The most common repair was suture over T-tube and only $17 \%$ of patients had a Roux-en-Y hepatico-jejunostomy. In this study, $59 \%$ of the injuries were Hannover Grade C1 ( $<5 \mathrm{~mm}$ lesion). Strictures were reported at 6 months in $18 \%$ of patients.

Notably, two studies found that outreach programs in which an experienced HPB surgeon travels to the primary center can also achieve good outcomes $[174,176]$.
Together these studies suggest that early referral to a tertiary center with experienced hepatobiliary surgeons and associated interventional radiologic and endoscopic services appears necessary to ensure optimal results. In addition, abundant indirect evidence from other surgical domains has previously established a positive relationship between surgeon volume and surgical outcomes. Quantitative, pooled data from an umbrella systematic review covering 15 surgical procedures that included abdominal aortic aneurysm, colorectal cancer, esophagectomy, pancreatic cancer resection, and other procedures favored higher surgeon experience or volume [168]. Non-pooled results from individual studies on the Norwood procedure, trauma, bariatric surgery, radical prostatectomy, total knee arthroplasty, and coronary artery bypass also supported the same relationship between improved outcomes and surgeon volume.

Justification In summary, there is a strong clinical rationale and both direct and indirect evidence favoring specialty repair despite the very low certainty of direct evidence addressing this question. Consequently, the GDG invoked one of the 5 paradigmatic situations for a strong recommendation originating in this setting (potential for catastrophic harm) [34]. The complexity in assessing the extent of BDI and potential associated vascular injury, as well as the type of surgery entailed in the repair, are significantly different than for laparoscopic cholecystectomy. Therefore, high-volume experience in LC cannot be generalized to outcomes of repairs of BDI. No concerns were noted by the panel regarding the generalizability of the systematic review evidence. Further, the undesirable effects secondary to a potential delay related to a specialist referral were considered small or trivial, contingent to preparing the patient well for such a referral/transfer, i.e., placement of drains by primary surgeon. As such, the balance of benefit and harms were judged to strongly favor the intervention. Consequences of a poorly repaired or failed repair of BDI include catastrophic harms such as cholangitis, bile leak, biliary stricture, sepsis, need for reoperation or other interventions, and liver failure, all of which may potentially lead to death.

Recommendations for future studies Implementation pathways should be developed with creation of regional fast tract BDI referral pathways to offer advice and contribute to immediate treatment strategies when a BDI due to LC occurs.

Additional Panel Recommendation We suggest the development of national quality improvement initiatives for the prevention of bile duct injuries following cholecystectomy. The initiative(s) should be capable of identifying and characterizing bile duct injuries in the population under study.

One of the challenges of efforts to impact the rate of BDI is that it is extremely difficult to define the actual incidence 
and whether it might change over time. In order to determine this, large numbers of cholecystectomies need to be evaluated, and the administrative data that is currently used for this purpose from payors or other groups has inherent limitations, inaccuracies, and significant risk of bias. BDI is not just a U.S.A. or North American phenomenon, it is a worldwide phenomenon, which is why quality improvement initiatives should be at the national level whether within a country, a region, or within a professional surgical organization or society. The collective weight of the societies participating in this conference should work toward implementation strategies to move this recommendation forward.

\section{Discussion}

Bile duct injury is the most common severe complication of cholecystectomy. It is very morbid, greatly increases the cost of care, and often leads to litigation. For a procedure that is normally outpatient, with the expectation of an almost immediate return to normal activity, the consequences can be devastating. Since the 1992 NIH sponsored consensus conference on LC [177], there has been no consensus-type meeting focused on the safety of this operation despite substantial evolution of the field. This 2018 conference brought together experts from several surgical organizations with different principal areas of expertise to develop evidencebased recommendations in collaboration with the SAGES Guidelines committee.

In the initial consensus voting process, only three recommendations did not meet the $80 \%$ threshold for approval by the 25 voting experts (Questions 3, 9, and 13). Questions 9 and 13 were revised based on the meeting discussion and feedback and were re-voted on electronically by the expert panel and approved $(96.2 \%$ and $88.5 \%$ agreement, respectively). Audience voting participation at the meeting was concordant for approval with expert voting with discrepancies on Question 4 (88.5\% expert panel vs 77.3\% audience) and Question 6 Recommendation A1 (85\% expert panel vs $77.3 \%$ audience).

\section{Dissemination of BDI guidelines}

The dissemination of these guidelines broadly throughout the surgical community will require engagement of diverse stakeholders. Guideline recommendations will be promoted on society websites (such as the sages.org/safe-cholecystectomy-program) and through panel sessions at meetings of surgical societies. To reach an international audience, translation of the guideline document into other languages will be investigated. Engaging surgeons through social media such as specialty Facebook groups (e.g., SAGES Masters Biliary Facebook group) and networks of online communities which engage community surgeons are needed. The guidelines should also be distributed to hospitals, healthcare systems, healthcare plans, malpractice insurers, and patient safety organizations. Finally, dissemination into general surgery training programs in the US and worldwide will be critical to impacting the next generation of practicing surgeons.

\section{Implementation of guidelines and adoption}

Guideline implementation will be undertaken by an implementation team consisting of members of the GDG and stakeholder societies that will meet periodically until the next guideline update. The team will continually evaluate barriers and facilitators (e.g., through stakeholder surveys) of guideline adoption. The team will include members of the SAGES Safe Cholecystectomy Task Force and Guidelines Committee along with representatives from the other consensus conference society members. The team will also ensure professional development opportunities and coaching and monitor the effectiveness of guideline implementation using pre-specified outcome measures. This approach will help ensure that relevant changes are made to the existing implementation plan as needed.

\section{Limitations}

The quality of evidence of many studies was low with resultant moderate to high risk of bias for many key questions. This resulted in many conditional or expert opinion-based recommendations. For some questions, few relevant studies were available which precluded formulation of a recommendation. Randomized trials in which BDI is an outcome are not feasible because of the low frequency of BDI that would necessitate enrollment of a very large number of patients $(>5000)$ per arm. Proxy outcomes for BDI may be used in some cases such as identification of anatomy, but the degree of correlation with the primary outcome of BDI is unknown. A final limitation is that direct involvement of patients with BDI and their families was not included in the consensus meeting, although every effort was made to consider that perspective in the GDG deliberation process.

\section{Future research recommendations}

An important aspect of these guidelines is the provision of recommendations for future research studies. Areas for future investigation include the role of new imaging modalities in high-risk populations, risk stratification for surgery and timing of cholecystectomy, education and training strategies to reduce biliary injury, and development of national or society related registries. The low incidence of BDI at any one institution and the absence of national registries for 
tracking BDI makes the study of this problem and efforts to impact it challenging. Current observational studies are underpowered with limited generalizability, as most originate from single institutions and/or report sample sizes too small to adequately detect BDI. Studies with adequate sample size are often derived from claims or administrative data that are at high risk of bias and lack the clinical nuance necessary to identify key patient and operative elements critical to the prevention of BDI. Therefore, the development of national quality improvement initiatives for the identification and tracking of BDIs following cholecystectomy should be one of the most important steps taken going forward.

\section{Updating BDI guidelines}

These guidelines will be reviewed and updated within five years of publication. In addition, the literature on BDI and cholecystectomy will be monitored annually for new publications that pertain to the key questions and recommendations from this guideline. It is also anticipated that the recommendations for future research, based on evidence and knowledge gaps identified in this review, will lead to the formation of well-designed, prospective studies that will enhance understanding of areas of controversy in the field.

\section{Summary}

The persistence of BDI rates as the most serious complication of laparoscopic cholecystectomy despite technological advances requires a concerted intervention to enhance the safety of this common operation. The evidence-based guideline recommendations from this consensus effort are an important step toward recognition of key strategies surgeons can employ going forward and have considerable potential to positively impact patient outcomes. The identification of future research studies should lead to the design of clinical and educational research initiatives that can drive further improvement in the quality of surgical care for patients undergoing cholecystectomy.

Acknowledgements The Guideline Steering Group L. Michael Brunt, Daniel Deziel, Steven Strasberg, Dana Telem, Dimitrios Stefanidis. Sponsoring Society Leadership Horacio Asbun and L. Michael Brunt [SAGES], Rebecca Minter and Charles Vollmer [AHPBA], Gazi Zibari and Oscar Imventarza [IHPBA], Nat Soper [SSAT], and Jaap Bonjer [EAES]. Guideline Development Group Members:L. Michael Brunt, Dimitrios Stefanidis, Daniel Deziel, Dana Telem, Steven Strasberg, Raj Aggarwal, Horacio Asbun, Marian McDonald, Adnan Alseidi, Mike Ujiki, Taylor Riall, Chet Hammill. Saxon Connor, Carol-Anne Moulton, Phil Pucher, Rowan Parks, and Jaap Bonjer. GRADE and Evidence Review Methodology Team Mohamed Ansari, Dimitrios Stefanidis, Valerie Rofeberg, Rebecca Dirks. SAGES Support Staff
Brenda Castaneda -support for all activities of the consensus process and meeting planning, Shauna Bostian, SAGES librarian, Shelley Ginsburg, Development. *Prevention of Bile Duct Injury Consensus Group ${ }^{1}$ Domenech Asbun, MD; ${ }^{2}$ Chantel den Baaker, MD; ${ }^{3}$ Luigi Boni, MD; ${ }^{4}$ Ryan Campagna, MD; ${ }^{5}$ Eugene Ceppa, MD; ${ }^{6}$ Marie Crandall, MD; ${ }^{7}$ Chris Davis, MD; ${ }^{8}$ Shanley Deal, MD; ${ }^{5}$ Scott Dojels, MD; ${ }^{9}$ Ismael Domiguez-Rosado, MD; ${ }^{2}$ Leonie van Gastel, MD; ${ }^{10}$ Justin Gerard, MD; ${ }^{11}$ Daniel Hashimoto, MD; ${ }^{12}$ Ewen Harrison, MD; ${ }^{13}$ Sara Holden MD; ${ }^{14}$ Romeo Ignacio, MD $;{ }^{15}$ Oscar Imventarza, MD; ${ }^{16}$ Rohan Jeyarajah, MD; ${ }^{10}$ MacKenzie Landin; ${ }^{17}$ Charles Lawrence, MD; ${ }^{18}$ Marc Mesleh, MD; ${ }^{5}$ Sara Monafred, MD $;{ }^{19}$ Alessandro Paganini, MD; ${ }^{20} \mathrm{~B}$. Fernando Santos; ${ }^{21}$ Sadiq Sikora, MD; ${ }^{5}$ Tim Schaffner, MD; ${ }^{22}$ Nate Stoikes, MD; ${ }^{23}$ Bailey Su, MD; ${ }^{24}$ Megan Thomas; ${ }^{10}$ Ben Veenstra, MD;

${ }^{25}$ Waala Abdelmoaty, MD; and ${ }^{2}$ Eline Zwart, MD. ${ }^{1}$ University of California San Francisco-Fresno, Fresno, CA $;{ }^{2}$ VUmc University Medical Centre, Amsterdam, NE; ${ }^{3}$ Policlinico Hospital, University of Milan, Milan, Italy; ${ }^{4}$ Northwestern University school of Medicine, Chicago, IL; ${ }^{5}$ Indiana University School of Medicine, Indianapolis, IN; ${ }^{6}$ University of Florida College of Medicine, Jacksonville, FL; ${ }^{7}$ Medical College of Wisconsin, Milwaukee, WI; ${ }^{8}$ Virginia Mason Medical Center, Seattle, WA; ${ }^{9}$ National Institute of Medical Science and Nutrition, Mexico City, Mexico; ${ }^{10}$ Rush University Medical Center, Chicago, IL; ${ }^{11}$ Massachusetts General Hospital/Harvard Medical School, Boston, MA; ${ }^{12}$ University of Edinburgh and Royal Infirmary of Edinburgh, Edinburgh, Scotland, ${ }^{13}$ Washington University School of Medicine, St. Louis, MO; ${ }^{14}$ University Naval Medical Center, San Diego, CA; ${ }^{15}$ Hospital Dr Juan P Garrahan, Buenos Aires, Argentina; ${ }^{16}$ Methodist Dallas Medical Center, Dallas, TX; ${ }^{17}$ University of Arizona, Tucson, AZ; ${ }^{18}$ Advocate Medical Group, Oak Lawn, IL; ${ }^{19}$ Sapienza University of Rome, Italy; ${ }^{20}$ Dartmouth University School of Medicine, Concord, $\mathrm{NH}^{21}$ Sakra World Hospital Bangalore, India; ${ }^{22}$ University of Tennessee Health sciences Center, Memphis, TN; ${ }^{23}$ NorthShore University Health System, Chicago, IL; ${ }^{24}$ Christchurch Hospital, Canterbury District Health Board, NZ; ${ }^{25}$ Providence Medical Center, Portland OR.

Funding The consensus meeting was supported by Grants from the SAGES Education and Research Foundation and an R-13 conference Grant from the National Institute of Diabetes and Digestive and Kidney Diseases of the National Institutes of Health (NIDDK Award Number R13DK120271-01). The content is solely the responsibility of the authors and does not necessarily represent the official views of the National Institutes of Health. We also acknowledge consensus day meeting support by unrestricted education grants from Intuitive Surgical, Medtronic. Karl Storz Endoscopy, Stryker Endoscopy, Boston Scientific, and Ethicon, Inc.

\section{Compliance with ethical standards}

Disclosures Dr. Raj Aggarwal has been a consultant for Applied Medical; Dr. Adnan Alseidi is a consultant for Johnson \& Johnson; Dr. Horacio Asbun has received honoraria from Medtronic for speaking/teaching; Dr. Jaap Bonjer has research grant support from Applied Medical, Johnson \& Johnson, and Medtronic, institutional educational grant support from Stryker Endoscopy, and honoraria from Olympus for speaking/teaching; Dr. Michael Brunt has institutional research support from Gore Medical and Karl Storz Endoscopy and honoraria for speaking/ teaching from Intuitive Surgical; Dr. Chet Hammill has been a consultant for Medtronic, Intuitive Surgical, and Novadaq; Dr. Philip Pucher is a consultant for Fundamental Surgery; Dr. Dana Telem has received honoraria for speaking/teaching from Gore Medical and Medtronic; Dr. Mike Ujiki is a consultant for Applied Endosurgical, Boston Scientific, and Olympus and has received honoraria for speaking/teaching from Gore Medical and Medtronic. Drs. Daniel Deziel, Steven Strasberg, Marian McDonald, Taylor Riall, Carol-Anne Moulton, Rowan Parks, Mohammed Ansari, Saxon Connor, Rebecca Dirks, Blaire Anderson, 
Maria Altieri, Levan Tsamalaidze, and Dimitrios Stefanidis have no conflicts of interest or financial ties to disclose.

\section{References}

1. Soper NJ, Stockmann PT, Dunnegan DL et al (1992) Laparoscopic cholecystectomy. The new 'gold standard'? Arch Surg 127(8):917-921

2. Meyers WC (1991) A prospective analysis of 1518 laparoscopic cholecystectomies. The Southern Surgeons Club. N Engl J Med 324(16): 1073-1078

3. Davidoff AM, Pappas TN, Murray EA et al (1992) Mechanisms of major biliary injury during laparoscopic cholecystectomy. Ann Surg 215(3): 196-202

4. Adamsen S, Hansen OH, Funch-Jensen P et al (1997) Bile duct injury during laparoscopic cholecystectomy: a prospective nationwide series. J Am Coll Surg 184(6):571-578

5. Roslyn JJ, Binns GS, Hughes EF et al (1993) Open cholecystectomy. A contemporary analysis of 42,474 patients. Ann Surg 218(2):129-137

6. Deziel DJ (1994) Complications of cholecystectomy. Incidence, clinical manifestations, and diagnosis. Surg Clin N Am 74(4):809-823

7. Schwaitzberg SD, Scott DJ, Jones DB et al (2014) Threefold increased bile duct injury rate is associated with less surgeon experience in an insurance claims database: more rigorous training in biliary surgery may be needed. Surg Endosc 28(11):3068-3073

8. Tornqvist B, Stromberg C, Akre O et al (2015) Selective intraoperative cholangiography and risk of bile duct injury during cholecystectomy. Br J Surg 102(8):952-958

9. Lilley EJ, Scott JW, Jiang W et al (2017) Intraoperative cholangiography during cholecystectomy among hospitalized medicare beneficiaries with non-neoplastic biliary disease. Am J Surg 214(4):682-686

10. Barrett M, Asbun HJ, Chien HL et al (2018) Bile duct injury and morbidity following cholecystectomy: a need for improvement. Surg Endosc 32(4):1683-1688

11. Pucher PH, Brunt LM, Davies N et al (2018) Outcome trends and safety measures after 30 years of laparoscopic cholecystectomy: a systematic review and pooled data analysis. Surg Endosc 32(5):2175-2183

12. Fong ZV, Pitt HA, Strasberg SM et al (2018) Diminished survival in patients with bile leak and ductal injury: management strategy and outcomes. J Am Coll Surg 226(4):568-576

13. Tornqvist B, Stromberg C, Persson G et al (2012) Effect of intended intraoperative cholangiography and early detection of bile duct injury on survival after cholecystectomy: population based cohort study. BMJ 345:e6457

14. Navez B, Ungureanu F, Michiels M et al (2012) Surgical management of acute cholecystitis: results of a 2-year prospective multicenter survey in Belgium. Surg Endosc 26(9):2436-2445

15. Diamantis T, Tsigris C, Kiriakopoulos A et al (2005) Bile duct injuries associated with laparoscopic and open cholecystectomy: an 11-year experience in one institute. Surg Today 35(10):841-845

16. Melton GB, Lillemoe KD, Cameron JL et al (2002) Major bile duct injuries associated with laparoscopic cholecystectomy: effect of surgical repair on quality of life. Ann Surg 235(6):888-895
17. Tornqvist B, Zheng Z, Ye W et al (2009) Long-term effects of iatrogenic bile duct injury during cholecystectomy. Clin Gastroenterol Hepatol 7(9):1013-1018

18. Booij KAC, de Reuver PR, van Dieren S et al (2018) Longterm impact of bile duct injury on morbidity, mortality, quality of life, and work related limitations. Ann Surg 268(1):143-150

19. Halbert C, Pagkratis S, Yang J et al (2016) Beyond the learning curve: incidence of bile duct injuries following laparoscopic cholecystectomy normalize to open in the modern era. Surg Endosc 30(6):2239-2243

20. MacLean TR (2005) Monetary lessons from litigation involving laparoscopic cholecystectomy. Amer Surg 71:606-612

21. Roy PG, Soonawalla ZF, Grant HW (2009) Medicolegal costs of bile duct injuries incurred during laparoscopic cholecystectomy. HPB (Oxford) 11(2):130-134

22. Perera MT, Silva MA, Shah AJ et al (2010) Risk factors for litigation following major transectional bile duct injury sustained at laparoscopic cholecystectomy. World J Surg 34(11):2635-2641

23. Gartland RM, Bloom JP, Fong ZV et al (2019) What have we learned from malpractice claims involving the surgical management of benign biliary disease? A 128 million dollar question. Ann Surg 269(5):785-791

24. Pucher PH, Brunt LM, Fanelli RD et al (2015) SAGES expert Delphi consensus: critical factors for safe surgical practice in laparoscopic cholecystectomy. Surg Endosc 29(11):3074-3085

25. Kung J, Chiappelli F, Cajulis OO et al (2010) From systematic reviews to clinical recommendations for evidence-based health care: Validation of revised assessment of multiple systematic reviews (R-AMSTAR) for grading of clinical relevance. Open Dent J 4:84-91

26. Viechtbauer W (2010) Conducting meta-analyses in $\mathrm{R}$ with the metafor package. J Stat Softw 36:1-48

27. Review Manager (RevMan) [Computer program] (2014) Version 5.3. [computer program]. Copenhagen: The Nordic Cochrane Centre, The Cochrane Collaboration

28. Higgins JG (2011) Cochrane Handbook for Systematic Reviews of Interventions [Internet]. 5.1.0. The Cochrane Collaboration https://handbook-5-1.cochrane.org/

29. Schünemann H, Brożek J, Guyatt G, et al (2013) Handbook for grading the quality of evidence and the strength of recommendations using the GRADE approach [Internet]. https://gdt.grade pro.org/app/handbook/handbook.html

30. Balshem H, Helfand M, Schunemann HJ et al (2011) GRADE guidelines: 3. Rating the quality of evidence. J Clin Epidemiol 64(4):401-406

31. Alonso-Coello P, Oxman AD, Moberg J et al (2016) GRADE Evidence to Decision (EtD) frameworks: a systematic and transparent approach to making well informed healthcare choices. 2: Clinical practice guidelines. BMJ 353:i2089

32. Alonso-Coello P, Schunemann HJ, Moberg J et al (2016) GRADE Evidence to Decision (EtD) frameworks: a systematic and transparent approach to making well informed healthcare choices. 1: Introduction. BMJ 353:i2016

33. GRADEpro GDT: GRADEpro Guideline Development Tool [Software] [computer program]. McMaster University: 2015 (developed by Evidence Prime, Inc. gradepro.org

34. Neumann I, Santesso N, Akl EA et al (2016) A guide for health professionals to interpret and use recommendations in guidelines developed with the GRADE approach. J Clin Epidemiol 72:45-55

35. Schunemann HJ, Wiercioch W, Etxeandia I et al (2014) Guidelines 2.0: systematic development of a comprehensive checklist for a successful guideline enterprise. CMAJ 186(3):E123-E142

36. Graham R et al (2011) Committee on standards for developing trustworthy clinical practice guidelines BoHCS. In: Graham R, 
Wolman DM, Greenfield S, Steinberg E (eds) clinical practice guidelines we can trust. National Academies Press, Boca Raton

37. Qaseem A, Forland F, Macbeth F et al (2012) Guidelines International Network: toward international standards for clinical practice guidelines. Ann Intern Med 156(7):525-531

38. Schunemann HJ, Al-Ansary LA, Forland F et al (2015) Guidelines international network: principles for disclosure of interests and management of conflicts in guidelines. Ann Intern Med 163(7):548-553

39. Avgerinos C, Kelgiorgi D, Touloumis Z et al (2009) One thousand laparoscopic cholecystectomies in a single surgical unit using the "critical view of safety" technique. J Gastrointest Surg 13(3):498-503

40. Sanjay P, Fulke JL, Exon DJ (2010) 'Critical view of safety' as an alternative to routine intraoperative cholangiography during laparoscopic cholecystectomy for acute biliary pathology. J Gastrointest Surg 14(8):1280-1284

41. Tsalis K, Antoniou N, Koukouritaki Z et al (2015) Open-access technique and "critical view of safety" as the safest way to perform laparoscopic cholecystectomy. Surg Laparosc Endosc Percutan Tech 25(2):119-124

42. Yegiyants S, Collins JC (2008) Operative strategy can reduce the incidence of major bile duct injury in laparoscopic cholecystectomy. Am Surg 74(10):985-987

43. Singh K, Ohri A (2006) Anatomic landmarks: their usefulness in safe laparoscopic cholecystectomy. Surg Endosc 20(11):1754-1758

44. Ji W, Li LT, Li JS (2006) Role of laparoscopic subtotal cholecystectomy in the treatment of complicated cholecystitis. Hepatobiliary Pancreat Dis Int 5(4):584-589

45. Nakajima J, Sasaki A, Obuchi T et al (2009) Laparoscopic subtotal cholecystectomy for severe cholecystitis. Surg Today 39:870-875

46. Palanivelu C, Jani K, Maheshkumar GS (2007) Single-center experience of laparoscopic cholecystectomy. J Laparoendosc Adv Surg Tech A 17(5):608-614

47. Cox MR, Wilson TG, Jeans PL et al (1994) Minimizing the risk of bile duct injury at laparoscopic cholecystectomy. World J Surg 18(3):422-426

48. Hunter JG (1991) Avoidance of bile duct injury during laparoscopic cholecystectomy. Am J Surg 162(1):71-76

49. Kaya B, Fersahoglu MM, Kilic F et al (2017) Importance of critical view of safety in laparoscopic cholecystectomy: a survey of 120 serial patients, with no incidence of complications. Ann Hepatobiliary Pancreat Surg 21(1):17-20

50. Booij KA, de Reuver PR, Nijsse B et al (2014) Insufficient safety measures reported in operation notes of complicated laparoscopic cholecystectomies. Surgery 155(3):384-389

51. Strasberg SM, Eagon CJ, Drebin JA (2000) The "hidden cystic duct" syndrome and the infundibular technique of laparoscopic cholecystectomy-the danger of the false infundibulum. J Am Coll Surg 191(6):661-667

52. Nijssen MA, Schreinemakers JM, Meyer Z et al (2015) Complications after laparoscopic cholecystectomy: a video evaluation study of whether the critical view of safety was reached. World J Surg 39(7):1798-1803

53. Kohn JF, Trenk A, Kuchta K et al (2018) Characterization of common bile duct injury after laparoscopic cholecystectomy in a high-volume hospital system. Surg Endosc 32(3):1184-1191

54. Buddingh KT, Hofker HS, ten Cate Hoedemaker HO et al (2011) Safety measures during cholecystectomy: results of a nationwide survey. World J Surg 35(6):1235-1241

55. Vettoretto N, Saronni C, Harbi A et al (2011) Critical view of safety during laparoscopic cholecystectomy. JSLS 15(3):322-325
56. Hussain A (2011) Difficult laparoscopic cholecystectomy: current evidence and strategies of management. Surg Laparosc Endosc Percutan Tech 21(4):211-217

57. Gupta A, Agarwal PN, Kant R et al (2004) Evaluation of fundusfirst laparoscopic cholecystectomy. JSLS 8(3):255-258

58. Ichihara T, Takada M, Ajiki T et al (2004) Tape ligature of cystic duct and fundus-down approach for safety laparoscopic cholecystectomy: outcome of 500 patients. Hepatogastroenterology 51(56):362-364

59. Mahmud S, Masaud M, Canna K et al (2002) Fundus-first laparoscopic cholecystectomy. Surg Endosc 16(4):581-584

60. Martin IG, Dexter SP, Marton J et al (1995) Fundus-first laparoscopic cholecystectomy. Surg Endosc 9(2):203-206

61. Neri V, Ambrosi A, Fersini A et al (2007) Antegrade dissection in laparoscopic cholecystectomy. JSLS 11(2):225-228

62. Rosenberg J, Leinskold T (2004) Dome down laparoscopic cholecystectomy. Scand J Surg 93(1):48-51

63. Palanivelu C, Rajan PS, Jani K et al (2006) Laparoscopic cholecystectomy in cirrhotic patients: the role of subtotal cholecystectomy and its variants. J Am Coll Surg 203(2):145-151

64. Tuveri M, Calo PG, Medas F et al (2008) Limits and advantages of fundus-first laparoscopic cholecystectomy: lessons learned. $\mathrm{J}$ Laparoendosc Adv Surg Tech A 18(1):69-75

65. Tuveri M, Tuveri A (2009) Body-first laparoscopic cholecystectomy: a three-trocar technique for difficult gallbladders. J Laparoendosc Adv Surg Tech A 19(3):415-418

66. Wang YC, Yang HR, Chung PK et al (2006) Role of fundusfirst laparoscopic cholecystectomy in the management of acute cholecystitis in elderly patients. J Laparoendosc Adv Surg Tech A 16(2):124-127

67. Kato K, Kasai S, Matsuda M et al (1996) A new technique for laparoscopic cholecystectomy-retrograde laparoscopic cholecystectomy: an analysis of 81 cases. Endoscopy 28(4):356-359

68. Huang SM, Hsiao KM, Pan H et al (2011) Overcoming the difficulties in laparoscopic management of contracted gallbladders with gallstones: possible role of fundus-down approach. Surg Endosc 25(1):284-291

69. Yang FQ, Dai XW, Wang L et al (2002) Iatrogenic extrahepatic bile duct injury in 182 patients: causes and management. Hepatobiliary Pancreat Dis Int 1(2):265-269

70. Strasberg SM, Gouma DJ (2012) 'Extreme' vasculobiliary injuries: association with fundus-down cholecystectomy in severely inflamed gallbladders. HPB (Oxford) 14(1):1-8

71. Elshaer M, Gravante G, Thomas K et al (2015) Subtotal cholecystectomy for "difficult gallbladders": systematic review and meta-analysis. JAMA Surg 150(2):159-168

72. Soleimani M, Mehrabi A, Mood ZA et al (2007) Partial cholecystectomy as a safe and viable option in the emergency treatment of complex acute cholecystitis: a case series and review of the literature. Am Surg 73(5):498-507

73. Beldi G, Glattli A (2003) Laparoscopic subtotal cholecystectomy for severe cholecystitis. Surg Endosc 17(9):1437-1439

74. Chowbey PK, Sharma A, Khullar R et al (2000) Laparoscopic subtotal cholecystectomy: a review of 56 procedures. J Laparoendosc Adv Surg Tech A 10(1):31-34

75. Horiuchi A, Watanabe Y, Doi T et al (2008) Delayed laparoscopic subtotal cholecystectomy in acute cholecystitis with severe fibrotic adhesions. Surg Endosc 22(12):2720-2723

76. Hubert C, Annet L, van Beers BE et al (2010) The "inside approach of the gallbladder" is an alternative to the classic Calot's triangle dissection for a safe operation in severe cholecystitis. Surg Endosc 24(10):2626-2632

77. Kuwabara J, Watanabe Y, Kameoka K et al (2014) Usefulness of laparoscopic subtotal cholecystectomy with operative cholangiography for severe cholecystitis. Surg Today 44(3):462-465 
78. Michalowski K, Bornman PC, Krige JE et al (1998) Laparoscopic subtotal cholecystectomy in patients with complicated acute cholecystitis or fibrosis. Br J Surg 85(7):904-906

79. Philips JA, Lawes DA, Cook AJ et al (2008) The use of laparoscopic subtotal cholecystectomy for complicated cholelithiasis. Surg Endosc 22(7):1697-1700

80. Sinha I, Smith ML, Safranek P et al (2007) Laparoscopic subtotal cholecystectomy without cystic duct ligation. Br J Surg 94(12):1527-1529

81. Dissanaike S (2016) A step-by-step guide to laparoscopic subtotal fenestrating cholecystectomy: a damage control approach to the difficult gallbladder. J Am Coll Surg 223(2):e15-e18

82. Lidsky ME, Speicher PJ, Ezekian B et al (2017) Subtotal cholecystectomy for the hostile gallbladder: failure to control the cystic duct results in significant morbidity. HPB (Oxford) 19(6):547-556

83. Matsui Y, Hirooka S, Kotsuka M et al (2018) Use of a piece of free omentum to prevent bile leakage after subtotal cholecystectomy. Surgery 164(3):419-423

84. Shingu Y, Komatsu S, Norimizu S et al (2016) Laparoscopic subtotal cholecystectomy for severe cholecystitis. Surg Endosc 30(2):526-531

85. van Dijk AH, Donkervoort SC, Lameris W et al (2017) Shortand long-term outcomes after a reconstituting and fenestrating subtotal cholecystectomy. J Am Coll Surg 225(3):371-379

86. Kim Y, Wima K, Jung AD et al (2017) Laparoscopic subtotal cholecystectomy compared to total cholecystectomy: a matched national analysis. J Surg Res 218:316-321

87. Sewefy AM, Hassanen AM, Atyia AM et al (2017) Retroinfundibular laparoscopic cholecystectomy versus standard laparoscopic cholecystectomy in difficult cases. Int J Surg 43:75-80

88. Lee J, Miller P, Kermani R et al (2012) Gallbladder damage control: compromised procedure for compromised patients. Surg Endosc 26(10):2779-2783

89. Buddingh KT, Morks AN, ten Cate Hoedemaker HO et al (2012) Documenting correct assessment of biliary anatomy during laparoscopic cholecystectomy. Surg Endosc 26(1):79-85

90. Emous M, Westerterp M, Wind J et al (2010) Registering the critical view of safety: photo or video? Surg Endosc 24(10):2527-2530

91. Plaisier PW, Pauwels MM, Lange JF (2001) Quality control in laparoscopic cholecystectomy: operation notes, video or photo print? HPB (Oxford) 3(3):197-199

92. Wauben LS, van Grevenstein WM, Goossens RH et al (2011) Operative notes do not reflect reality in laparoscopic cholecystectomy. Br J Surg 98(10):1431-1436

93. Sanford DE, Strasberg SM (2014) A simple effective method for generation of a permanent record of the Critical View of Safety during laparoscopic cholecystectomy by intraoperative "doublet" photography. J Am Coll Surg 218(2):170-178

94. Ivers NM, Grimshaw JM, Jamtvedt G et al (2014) Growing literature, stagnant science? Systematic review, meta-regression and cumulative analysis of audit and feedback interventions in health care. J Gen Intern Med 29(11):1534-1541

95. Carlson MA, Ludwig KA, Frantizides CT et al (1993) Routine or selective intraoperative cholangiography in laparoscopic cholecystectomy. J Laparoendosc Surg 3:27-33

96. Z'Graggen K, Wehrli H, Metzger A et al (1998) Complications of laparoscopic cholecystectomy in Switzerland. A prospective 3-year study of 10,174 patients. Swiss Association of Laparoscopic and Thoracoscopic Surgery. Surg Endosc 12(11):1303-1310

97. Flum DR, Koepsell T, Heagerty P et al (2001) Common bile duct injury during laparoscopic cholecystectomy and the use of intraoperative cholangiography: adverse outcome or preventable error? Arch Surg 136(11):1287-1292

98. Ludwig K, Bernhardt J, Steffen H et al (2002) Contribution of intraoperative cholangiography to incidence and outcome of common bile duct injuries during laparoscopic cholecystectomy. Surg Endosc 16(7):1098-1104

99. Flum DR, Dellinger EP, Cheadle A et al (2003) Intraoperative cholangiography and risk of common bile duct injury during cholecystectomy. JAMA 289(13):1639-1644

100. Metcalfe MS, Ong T, Bruening MH et al (2004) Is laparoscopic intraoperative cholangiogram a matter of routine? Am J Surg 187(4):475-481

101. Hobbs MS, Mai Q, Knuiman MW et al (2006) Surgeon experience and trends in intraoperative complications in laparoscopic cholecystectomy. Br J Surg 93(7):844-853

102. Giger U, Ouaissi M, Schmitz SF et al (2011) Bile duct injury and use of cholangiography during laparoscopic cholecystectomy. Br J Surg 98(3):391-396

103. Sheffield KM, Riall TS, Han Y et al (2013) Association between cholecystectomy with vs without intraoperative cholangiography and risk of common duct injury. JAMA 310(8):812-820

104. El-Dhuwaib Y, Slavin J, Corless DJ et al (2016) Bile duct reconstruction following laparoscopic cholecystectomy in England. Surg Endosc 30(8):3516-3525

105. Waage A, Nilsson M (2006) Iatrogenic bile duct injury: a population-based study of 152776 cholecystectomies in the Swedish Inpatient Registry. Arch Surg 141(12):1207-1213

106. Ladocsi LT, Benitez LD, Filippone DR et al (1997) Intraoperative cholangiography in laparoscopic cholecystectomy: a review of 734 consecutive cases. Am Surg 63(2):150-156

107. Ford JA, Soop M, Du J et al (2012) Systematic review of intraoperative cholangiography in cholecystectomy. Br J Surg 99(2):160-167

108. Ding GQ, Cai W, Qin MF (2015) Is intraoperative cholangiography necessary during laparoscopic cholecystectomy for cholelithiasis? World J Gastroenterol 21(7):2147-2151

109. Strasberg SM, Brunt LM (2017) The Critical view of safety: why it is not the only method of ductal identification within the standard of care in laparoscopic cholecystectomy. Ann Surg 265(3):464-465

110. Woods MS, Traverso LW, Kozarek RA et al (1995) Biliary tract complications of laparoscopic cholecystectomy are detected more frequently with routine intraoperative cholangiography. Surg Endosc 9(10):1076-1080

111. Gigot J, Etienne J, Aerts R et al (1997) The dramatic reality of biliary tract injury during laparoscopic cholecystectomy An anonymous multicenter Belgian survey of 65 patients. Surg Endosc 11(12):1171-1178

112. Slater K, Strong RW, Wall DR et al (2002) Iatrogenic bile duct injury: the scourge of laparoscopic cholecystectomy. ANZ J Surg 72(2):83-88

113. Machi J, Tateishi T, Oishi AJ et al (1999) Laparoscopic ultrasonography versus operative cholangiography during laparoscopic cholecystectomy: review of the literature and a comparison with open intraoperative ultrasonography. J Am Coll Surg 188(4):360-367

114. Biffl WL, Moore EE, Offner PJ et al (2001) Routine intraoperative laparoscopic ultrasonography with selective cholangiography reduces bile duct complications during laparoscopic cholecystectomy. J Am Coll Surg 193(3):272-280

115. Machi J, Johnson JO, Deziel DJ et al (2009) The routine use of laparoscopic ultrasound decreases bile duct injury: a multicenter study. Surg Endosc 23(2):384-388

116. Dip FD, Asbun D, Rosales-Velderrain A et al (2014) Cost analysis and effectiveness comparing the routine use of 
intraoperative fluorescent cholangiography with fluoroscopic cholangiogram in patients undergoing laparoscopic cholecystectomy. Surg Endosc 28(6):1838-1843

117. Dip F, Roy M, Lo Menzo E et al (2015) Routine use of fluorescent incisionless cholangiography as a new imaging modality during laparoscopic cholecystectomy. Surg Endosc 29(6):1621-1626

118. Prevot F, Rebibo L, Cosse C et al (2014) Effectiveness of intraoperative cholangiography using indocyanine green (versus contrast fluid) for the correct assessment of extrahepatic bile ducts during day-case laparoscopic cholecystectomy. J Gastrointest Surg 18(8):1462-1468

119. Osayi SN, Wendling MR, Drosdeck JM et al (2015) Near-infrared fluorescent cholangiography facilitates identification of biliary anatomy during laparoscopic cholecystectomy. Surg Endosc 29(2):368-375

120. Vlek SL, van Dam DA, Rubinstein SM et al (2017) Biliary tract visualization using near-infrared imaging with indocyanine green during laparoscopic cholecystectomy: results of a systematic review. Surg Endosc 31(7):2731-2742

121. Pesce A, Piccolo A, Lagreca G et al (2015) Utility of fluorescent cholangiography during laparoscopic cholecystectomy: a systematic review. World J Gastroenterol 21:7877-7883

122. Dip F, LoMenzo E, Sarotto L et al (2019) Randomized trial of near-infrared incisionless fluorescent cholangiography. Ann Surg 270:990-999

123. Mayumi T, Okamoto K, Takada T et al (2018) Tokyo Guidelines 2018: management bundles for acute cholangitis and cholecystitis. J Hepatobiliary Pancreat Sci 25(1):96-100

124. Yamashita Y, Takada T, Strasberg SM et al (2013) TG13 surgical management of acute cholecystitis. J Hepatobiliary Pancreat Sci 20(1):89-96

125. Hernandez M, Murphy B, Aho JM et al (2018) Validation of the AAST EGS acute cholecystitis grade and comparison with the Tokyo guidelines. Surgery 163(4):739-746

126. Tornquist B, Waage A, Zheng Z et al (2016) Severity of acute cholecystitis and risk of iatrogenic bile duct injury during cholecystectomy, a population-based case-control study. World $\mathbf{J}$ Surg 40(5):1060-1067

127. Joseph B, Jehan F, Dacey M et al (2018) Evaluating the relevance of the 2013 Tokyo Guidelines for the diagnosis and management of cholecystitis. J Am Coll Surg 227(1):38-43

128. Cao AM, Eslick GD, Cox MR (2015) Early cholecystectomy is superior to delayed cholecystectomy for acute cholecystitis: a meta-analysis. J Gastrointest Surg 19(5):848-857

129. de Mestral C, Rotstein OD, Laupacis A et al (2014) Comparative operative outcomes of early and delayed cholecystectomy for acute cholecystitis: a population-based propensity score analysis. Ann Surg 259(1):10-15

130. Roulin D, Saadi A, Di Mare L et al (2016) Early versus delayed cholecystectomy for acute cholecystitis, are the 72 hours still the rule? A randomizedtrial. Ann Surg 264(5):717-722

131. Blohm M, Osterberg J, Sandblom G et al (2017) The sooner, the better? The importance of optimal timing of cholecystectomy in acute cholecystitis: data from the National Swedish Registry for Gallstone Surgery, GallRiks. Gastrointest Surg 21(1):33-40

132. Polo M, Duclos A, Polazzi S et al (2015) Acute cholecystitisoptimal timing for early cholecystectomy: a French nationwide study. J Gastrointest Surg 19(11):2003-2010

133. Cao AM, Eslick GD, Cox MR (2016) Early laparoscopic cholecystectomy is superior to delayed cholecystectomy for acute cholecystitis: a meta-analysis of case-control studies. Surg Endosc 30(3):1172-1182

134. Endo I, Takada T, Hwang TL et al (2017) Optimal treatment strategy for acute cholecystitis based on predictive factors:
Japan-Taiwan multicenter cohort study. J Hepatobiliary Pancreat Sci 24(6):346-361

135. Yokoe M, Takada T, Mayumi T et al (2011) Accuracy of the Tokyo Guidelines for the diagnosis of acute cholangitis and cholecystitis taking into consideration the clinical practice pattern in Japan. J Hepatobiliary Pancreat Sci 18(2):250-257

136. Fried GM, Barkun JS, Sigman HH et al (1994) Factors determining conversion to laparotomy in patients undergoing laparoscopic cholecystectomy. Am J Surg 167(1):35-39

137. Sanabria JR, Gallinger S, Croxford R et al (1994) Risk factors in elective laparoscopic cholecystectomy for conversion to open cholecystectomy. J Am Coll Surg 179(6):696-704

138. Gutt CN, Encke J, Koninger J et al (2013) Acute cholecystitis: early versus delayed cholecystectomy, a multicenter randomized trial (ACDC study, NCT00447304). Ann Surg 258(3):385-393

139. Joseph M, Phillips MR, Farrell TM et al (2012) Single incision laparoscopic cholecystectomy is associated with a higher bile duct injury rate: a review and a word of caution. Ann Surg 256(1):1-6

140. Arezzo A, Passera R, Forcignano E et al (2018) Single-incision laparoscopic cholecystectomy is responsible for increased adverse events: results of a meta-analysis of randomized controlled trials. Surg Endosc 32(9):3739-3753

141. Qiu J, Yuan H, Chen S et al (2013) Single-port versus conventional multiport laparoscopic cholecystectomy: a meta-analysis of randomized controlled trials and nonrandomized studies. J Laparoendosc Adv Surg Tech A 23(10):815-831

142. Milas M, Devedija S, Trjulja V (2014) Single incision versus standard multiport laparoscopic cholecystectomy: updated systematic review and meta-analysis of randomized trials. Surgeon 12:271-289

143. Gurusamy K, Vaughan J, Rossi M et al (2014) Fewer-thanfour ports versus four ports for laparoscopic cholecystectomy. Cochrane Database Syst Rev 20:CD007109

144. Winbladh A, Gullstrand P, Svanvik J et al (2009) Systematic review of cholecystostomy as a treatment option in acute cholecystitis. HPB (Oxford) 11(3):183-193

145. de Mestral C, Gomez D, Haas B et al (2013) Cholecystostomy: a bridge to hospital discharge but not delayed cholecystectomy. J Trauma Acute Care Surg 74(1):175-179

146. Alvino DML, Fong ZV, McCarthy CJ et al (2017) Long-term outcomes following percutaneous cholecystostomy tube placement for treatment of acute calculous cholecystitis. J Gastrointest Surg 21(5):761-769

147. Horn T, Christensen SD, Kirkegard J et al (2015) Percutaneous cholecystostomy is an effective treatment option for acute calculous cholecystitis: a 10-year experience. HPB (Oxford) 17(4):326-331

148. Khasawneh MA, Shamp A, Heller S et al (2015) Successful laparoscopic cholecystectomy after percutaneous cholecystostomy tube placement. J Trauma Acute Care Surg 78(1):100-104

149. Jang WS, Lim JU, Joo KR et al (2015) Outcome of conservative percutaneous cholecystostomy in high-risk patients with acute cholecystitis and risk factors leading to surgery. Surg Endosc 29(8):2359-2364

150. McKay A, Abulfaraj M, Lipschitz J (2012) Short- and long-term outcomes following percutaneous cholecystostomy for acute cholecystitis in high-risk patients. Surg Endosc 26(5):1343-1351

151. Noh SY, Gwon DI, Ko GY et al (2018) Role of percutaneous cholecystostomy for acute acalculous cholecystitis: clinical outcomes of 271 patients. Eur Radiol 28(4):1449-1455

152. Chung YH, Choi ER, Kim KM et al (2012) Can percutaneous cholecystostomy be a definitive management for acute acalculous cholecystitis? J Clin Gastroenterol 46(3):216-219 
153. Kirkegard J, Horn T, Christensen SD et al (2015) Percutaneous cholecystostomy is an effective definitive treatment option for acute acalculous cholecystitis. Scand J Surg 104(4):238-243

154. Ozyer U (2018) Long-term results of percutaneous cholecystostomy for definitive treatment of acute acalculous cholecystitis: a 10-year single-center experience. Acta Gastroenterol Belg 81(3):393-397

155. Loozen CS, van Santvoort HC, van Duijvendijk P et al (2018) Laparoscopic cholecystectomy versus percutaneous catheter drainage for acute cholecystitis in high risk patients (CHOCOLATE): multicentre randomised clinical trial. BMJ 363:k3965

156. Connor SJ, Perry W, Nathanson L et al (2014) Using a standardized method for laparoscopic cholecystectomy to create a concept operation-specific checklist. HPB (Oxford) 16(5):422-429

157. Misra M, Schiff J, Rendon G et al (2005) Laparoscopic cholecystectomy after the learning curve: what should we expect? Surg Endosc 19(9):1266-1271

158. Harrison VL, Dolan JP, Pham TH et al (2011) Bile duct injury after laparoscopic cholecystectomy in hospitals with and without surgical residency programs: is there a difference? Surg Endosc 25(6):1969-1974

159. Nijssen MA, Schreinemakers JM, van der Schelling GP et al (2016) Improving critical view of safety in laparoscopic cholecystectomy by teaching interventions. J Surg Educ 73(3):442-447

160. Stefanidis D, Chintalapudi N, Anderson-Montoya B et al (2017) How often do surgeons obtain the critical view of safety during laparoscopic cholecystectomy? Surg Endosc 31(1):142-146

161. Min H, Morales DR, Orgill D et al (2015) Systematic review of coaching to enhance surgeons' operative performance. Surgery 158(5):1168-1191

162. Singh P, Aggarwal R, Tahir M et al (2015) A randomized controlled study to evaluate the role of video-based coaching in training laparoscopic skills. Ann Surg 261(5):862-869

163. Hakamada K, Narumi S, Toyoki Y et al (2008) Intraoperative ultrasound as an educational guide for laparoscopic biliary surgery. World J Gastroenterol 14(15):2370-2376

164. Deal SB, Stefanidis D, Telem D et al (2017) Evaluation of crowdsourced assessment of the critical view of safety in laparoscopic cholecystectomy. Surg Endosc 31(12):5094-5100

165. Madani A, Watanabe Y, Feldman LS et al (2015) Expert intraoperative judgment and decision-making: defining the cognitive competencies for safe laparoscopic cholecystectomy. J Am Coll Surg 221(5):931-940

166. Chen CB, Palazzo F, Doane SM et al (2017) Increasing resident utilization and recognition of the critical view of safety during laparoscopic cholecystectomy: a pilot study from an academic medical center. Surg Endosc 31(4):1627-1635

167. Archer SB, Brown DW, Smith CD et al (2001) Bile duct injury during laparoscopic cholecystectomy: results of a national survey. Ann Surg 234(4):549-558

168. Morche J, Mathes T, Pieper D (2016) Relationship between surgeon volume and outcomes: a systematic review of systematic reviews. Syst Rev 5(1):204

169. Perera MT, Silva MA, Hegab B et al (2011) Specialist early and immediate repair of post-laparoscopic cholecystectomy bile duct injuries is associated with an improved long-term outcome. Ann Surg 253(3):553-560

170. Stewart L, Way LW (2009) Laparoscopic bile duct injuries: timing of surgical repair does not influence success rate. A multivariate analysis of factors influencing surgical outcomes. HPB (Oxford) 11(6):516-522

171. Xu XD, Zhang YC, Gao P et al (2011) Treatment of major laparoscopic bile duct injury: a long-term follow-up result. Am Surg 77(12):1584-1588

172. de Reuver PR, Grossmann I, Busch OR et al (2007) Referral pattern and timing of repair are risk factors for complications after reconstructive surgery for bile duct injury. Ann Surg 245(5):763-770

173. Sicklick JK, Camp MS, Lillemoe KD et al (2005) Surgical management of bile duct injuries sustained during laparoscopic cholecystectomy: perioperative results in 200 patients. Ann Surg 241(5):786-792

174. Thomson BN, Parks RW, Madhavan KK et al (2006) Early specialist repair of biliary injury. Br J Surg 93(2):216-220

175. Rystedt J, Lindell G, Montgomery A (2016) Bile duct injuries associated with 55,134 cholecystectomies: treatment and outcome from a national perspective. World J Surg 40(1):73-80

176. Silva MA, Coldham C, Mayer AD et al (2008) Specialist outreach service for on-table repair of iatrogenic bile duct injuries-a new kind of 'travelling surgeon'. Ann R Coll Surg Engl 90(3):243-246

177. NIH Consensus conference (1993) Gallstones and laparoscopic cholecystectomy. JAMA 269(8):1018-1024

Publisher's Note Springer Nature remains neutral with regard to jurisdictional claims in published maps and institutional affiliations.

\section{Affiliations}

\section{Michael Brunt ${ }^{1}$ (1) . Daniel J. Deziel ${ }^{2}$. Dana A. Telem ${ }^{3}$. Steven M. Strasberg ${ }^{1} \cdot$ Rajesh Aggarwal $^{4}$. Horacio Asbun ${ }^{5}$. Jaap Bonjer ${ }^{6} \cdot$ Marian McDonald $^{7} \cdot$ Adnan Alseidi $^{8} \cdot$ Mike Ujiki $^{9} \cdot$ Taylor S. Riall $^{10} \cdot$ Chet Hammill $^{1}$. Carol-Anne Moulton ${ }^{11}$. Philip H. Pucher ${ }^{12}$. Rowan W. Parks ${ }^{13}$. Mohammed T. Ansari ${ }^{14}$. Saxon Connor ${ }^{15}$. Rebecca C. Dirks ${ }^{16}$. Blaire Anderson ${ }^{1} \cdot$ Maria S. Altieri ${ }^{1} \cdot$ Levan Tsamalaidze ${ }^{17}$. Dimitrios Stefanidis ${ }^{16}$. the Prevention of Bile Duct Injury Consensus Work Group}

1 Department of Surgery, Washington University School of Medicine, St. Louis, MO, USA

2 Rush University Medical Center, Chicago, IL, USA

3 University of Michigan School of Medicine, Ann Arbor, MI, USA

4 Thomas Jefferson University School of Medicine, Philadelphia, PA, USA
5 Miami Baptist Cancer Center, Miami, FL, USA

6 VUmc University Medical Centre, Amsterdam, The Netherlands

7 St. Luke's University and Health Network, Allentown, PA, USA

8 Virginia Mason Medical Center, Seattle, WA, USA 
9 NorthShore University Health System, Chicago, IL, USA

10 University of Arizona School of Medicine, Tucson, AZ, USA

11 University of Toronto, Toronto, CA, USA

12 Imperial College London, London, England

13 University of Edinburgh, Edinburgh, Scotland, UK
14 University of Ottawa, Ottawa, CA, USA

15 University of New Zealand, Christ Church, New Zealand

16 Indiana University School of Medicine, Indianapolis, IN, USA

17 Tbilisi State Medical University, Tbilisi, Georgia 